\title{
ENCUESTAS SOBRE SALARIO MÍNIMO Y REMUNERACIÓN DOCENTE: UN ESTADO DEL ARTE - 2008-2021
}

\section{ARTÍCULO ORIGINAL}

LIMA, Maria José Rocha ${ }^{1}$, RAMOS, Fernando Sadio²

LIMA, Maria José Rocha. RAMOS, Fernando Sadio. Encuestas sobre salario mínimo y remuneración docente: un estado del arte - 2008-2021. Revista Científica Multidisciplinar Núcleo do Conhecimento. Año. 06, Ed. 11, Vol. 08, págs. 100-133. Noviembre 2021. ISSN: 2448-0959, Enlace de acceso: https://www.nucleodoconhecimento.com.br/educacion-es/remuneracion-docente, DOI: 10.32749/nucleodoconhecimento.com.br/educacion-es/remuneracion-docente

\section{RESUMEN}

Este artículo presenta una encuesta sobre estudios sobre piso salarial y remuneración docente entre 2008 y 2021[3]. En este sentido, la revisión bibliográfica sobre el piso salarial del magisterio es una pieza fundamental. Con este fin, la metodología desarrollada para la búsqueda bibliográfica se basa en el uso científico y cuidadoso de la teoría de la Evidence-Based Practice (EBP) - en portugués, Práticas Baseadas em Evidências (PBE). Es un estado del arte que elimina uno de los factores más decisivos para la transformación de la realidad educativa: los estudios sobre el piso salarial y la remuneración de los maestros brasileños. En este estudio se expone otra contradicción entre discursos enfáticos o grandilohot en

\footnotetext{
${ }^{1}$ Estudiante de Doctorado en Educación de la Universidad Internacional Iberoamericana - UNINI -; Magíster en Educación de la Universidad Federal de Bahía-UFBA-, Psicopedagogía de la Universidad Cândido Mendes - AVM, Especialista en Psicoanálisis de la Asociación Brasileña de Estudios e Investigaciones en Psicoanálisis - ABEPP-, Especialista en Culturas Negras del Atlántico de la Universidad de Brasilia - UnB-, Especialista en Metodología de la Enseñanza de la Educación Superior, Facultad de Educación de Bahía - FEBA - Licenciatura de Formación Especial en Currículo de Bachillerato, en el Área de Ciencias de la Salud; Maestra de Primaria, egresada del Instituto Central de Educação Isaías Alves. ID DE ORCID: 0000-0003-1766-2169

2 Tutor. Doctor en Ciencias Sociales / Ciencias de la Educación, Programa Curricular, Profesorado e Instituciones Educativas, Universidad de Granada, España. Máster en Filosofía Contemporánea de la Universidad de Coimbra, Portugal. Licenciada en Filosofía por la Universidad de Coimbra, Portugal. Director de DEDICA Revista Educación y Humanidades. (0000-0001-7654-5638) - ORCID
}

RC: 101661

Disponible: https://www.nucleodoconhecimento.com.br/educacion-es/remuneraciondocente 
defensa de la valorización de la enseñanza y las prácticas de las autoridades políticas y educativas, llamándonos también la baja producción de monografías, disertaciones y tesis doctorales, en el mundo académico, sobre piso salarial y remuneración docente. Incluso con la proclamación de la apreciación del maestro como un factor decisivo para garantizar la calidad de la educación, han pasado más de diez años desde el establecimiento del piso salarial, sin embargo, alrededor del $60 \%$ de los municipios brasileños aún no lo han implementado y esto no tiene la reverberación esperada en los estudios académicos.

Palabras clave: Estado del arte, Suelo salarial, Retribución docente, Salario docente, Profesionalización docente.

\section{INTRODUCCIÓN}

En Brasil, desafortunadamente debido a una tradición cultural inicua, la garantía de la educación como derecho social estuvo marcada por un retraso secular y una lentitud impensable. Las causas de tal retraso educativo han sido señaladas por teóricos, como el sociólogo Florestan Fernandes (1989, p. 160), quien al analizar la historia brasileña identifica la dependencia económica, el oscurantismo de las clases dominantes y un conflicto permanente llevado al interior de la escuela, que ayuda poco a resolver problemas, como factores de retraso. Es como una medición ininterrumpida de la correlación de fuerzas. Así, hay disputas de proyecto escolar, del proyecto de valorización, o no, del docente; proyecto de sociedad; el proyecto del hombre, por fin, como una lucha política incesante. Lo que hace un gobierno, otro lo deshace. ¿Cuáles son estos intereses que mueven la no aplicación de la ley que instituyó el piso salarial? ¿Se expresarían las disputas sobre las que Florestan Fernandes nos habla, entre los escépticos de derecha o izquierda que casi siempre sabotean la educación en Brasil?

En 1932, el Manifiesto de los Pioneros de la Nueva Educación, que tuvo entre sus suscriptores más destacados a Fernandes de Azevedo y Anísio Teixeira, comienza el documento pidiendo que en la jerarquía de los problemas nacionales, ninguno 
sería superado por la educación, ni siquiera los de carácter económico. El famoso pensador de la educación Anísio Teixeira advirtió que "sin educación, democracia sería una palabra vana utilizada para justificar la triste farsa de un sufragio universal irrisorio" (LIMA, 2011, p. 66). Para Florestan, "un punto esencial es lo que concierne a la tradición cultural y lo que ha representado de limitación cultural del maestro, menos en teoría, que en la práctica (FERNANDES, 1898, p. 157).

La visión del magisterio como sacerdocio se ha cruzado y consolidado a través de los siglos. Esta concepción religiosa y tradicional en la cultura brasileña, bien construida en los primeros días de la colonización, cuando fue dirigida por religiosos, fue uno de los graves problemas que enfrentaron los maestros para su profesionalización y desempeño del trabajo escolar profesional. En esta tradición era, y es, inaceptable para el maestro discutir la remuneración; el maestro debe tomar el magisterio como una misión: ser idealista, ser pobre y feliz en el ejercicio de la profesión. No es raro que el maestro ni siquiera tenga dinero para comprar libros.

En 1827, el emperador Dom Pedro I concedió la Ley de Escuelas de Primeras Letras del 15 de octubre de 1827, estableciendo en el Art. 3 la remuneración de los maestros, un piso salarial nunca implementado. Su sucesor, don Pedro II, incluso afirmó que "si no fuera emperador, desearía ser maestro" y que no conocía "una misión mayor y más noble que la de dirigir la inteligencia joven y preparar a los hombres del futuro". El último monarca del Imperio de Brasil reinó durante casi 50 años y nada concreto hizo por la remuneración y el reconocimiento del maestro.

Las bellas y expresivas palabras pronunciadas y los actos legislativos de los emperadores de Brasil, de 1827 a 1889, no tuvieron las repercusiones anunciadas en la política de remuneración de los maestros. A pesar de la no implementación del piso de magisterio, el acto de crear el piso en 1827 fue emblemático. Todo esto compone la evidencia más elocuente de este desajuste entre el discurso y la práctica en la historia política de la remuneración de los maestros en las escuelas públicas brasileñas. 
Las autoridades brasileñas hablan con elocuencia sobre la importancia del maestro, sin embargo,

cheios de meras frases de efeito, demagógicas, insinceras, ou discursos oficiais apenas ressaltam no magistério o seu caráter de sacerdócio (que realmente), mas sem a contrapartida de oferecer as condições necessárias a que o professor possa atuar na plenitude dos seus recursos e das suas qualificações (TEIXEIRA, 1999, p. 9).

Estos discursos, que muchas veces se transmiten, desde la visión del magisterio como una misión de carácter religioso y/o asistencial/paternalista parecen funcionar, por regla general, inhibiendo a educadores, académicos, e incluso sindicalistas, de abordar y defender salarios, piso salarial, remuneración docente digna para el magisterio, de modo que cuando lo hacen, es con cierta tibieza.

La idea sobre el "maestro vocacional", una visión puramente subjetiva, tiene un impacto negativo en la tarea pedagógica, constituyendo una barrera para superar la visión errónea de que para enseñar, algunas habilidades son suficientes, sin tener en cuenta la complejidad de la tarea. La enseñanza no es trabajo para los laicos. La didáctica y la pedagogía son campos científicos con una importante acumulación de conocimiento.

Por lo tanto, se deben enfrentar dos serios desafíos para el desempeño del trabajo escolar profesional y el aumento de la calidad de la educación: el no reconocimiento de la enseñanza como profesión y la incertidumbre con respecto al propósito de la escuela. Para superar estos dos problemas, se debe hacer un movimiento fuerte que se oponga a la situación impensable que es que el profesor reciba piso salarial casi siempre muy por debajo de los salarios que reciben los profesionales con el mismo nivel de formación. Esta situación lo obliga a trabajar en varias escuelas al mismo tiempo y aún así a aceptar el desempeño del trabajo escolar en espacios inadecuados.

Los maestros trabajan en las condiciones más precarias: junto a baños fétidos, en escuelas con habitaciones divididas incluso por tabiques, sin agua, sin sala de estar.

RC: 101661

Disponible: https://www.nucleodoconhecimento.com.br/educacion-es/remuneraciondocente 
Trabajan con mayor frecuencia sin equipos básicos, como billeteras, escritorios, gabinetes, entre otros necesarios. En lugares distantes, inhóspitos e inseguros, las agresiones y asaltos a los maestros dentro de las escuelas son comunes.

Para 2020, 4,300 escuelas públicas no tenían baños, e Internet de banda ancha no llegó a 17,200 (20.5\%) en 2020. Además, 35.800 colegios continúan sin recogida de aguas residuales, el $26,6 \%$ del total, según el Censo Escolar 2019. Con respecto a los recursos didáctico-pedagógicos, los docentes, por no tenerlos, compiten injustamente con los recursos mediáticos, como estamos viendo en este periodo de pandemia. Covid-19 expuso la trágica situación de los maestros "escupiendo y tiza", sin mapas, globos terráqueos, ilustraciones, en el siglo 21 y en la era de la revolución tecnológica.

También es esencial, para la resolución de estos problemas, la definición clara del propósito de la escuela. Para ello, es necesario estimular y elevar la producción científica y un movimiento que promueva la superación de esta confusión establecida en relación con la función de la escuela: lugar de protección, refugio, depósito para niños o espacio único para la realización de labores escolares, que debe cumplir su propósito primordial de ofrecer los conocimientos y contenidos técnicos y científicos necesarios para la supervivencia simbólica.

Uno de los discursos más generalizados para la deconstrucción de esta visión del maestro-sacerdote fue pronunciado por el profesor de la Universidad de Bahía UFBA, periodista y escritor João Carlos Teixeira, en la Asamblea Legislativa de Bahía, en 1999, cuando dijo:

Por lamentável (e iníqua) tradição, no Brasil o professor costuma ser simultaneamente mártir e herói, quando deveria ser apenas (sobretudo) uma pessoa capacitada para o exercício da sua relevante missão social, prestigiada pela sociedade e amparada pelos poderes públicos, com remuneração à altura da importância de que o seu trabalho se reveste para toda a coletividade (TEIXEIRA, 1999, p. 9).

RC: 101661

Disponible: https://www.nucleodoconhecimento.com.br/educacion-es/remuneraciondocente 
Sólo en el siglo 21 se estableció por ley el Piso Nacional de Salario Profesional. Es así como el 16 de julio de 2008, el entonces Presidente de la República, Luiz Inácio Lula da Silva, sancionó la Ley 11.738/2008. Esta ley estableció el Piso Salarial Profesional Nacional para los profesionales de la educación pública básica - PSPN estableciendo un valor que será, obligatoriamente, ajustado cada año y "por debajo del cual la Unión, los Estados, el Distrito Federal y los Municipios no podrán fijar el salario inicial de las Carreras de la enseñanza pública de la educación básica, por el trayecto de, máximo de 40 (cuarenta) horas semanales" (BRASIL, 2008). Sin embargo, incluso después de esta espera secular, más de la mitad de los 5.570 municipios de Brasil no cumplen.

Ante este escenario, y de acuerdo con la propuesta, seleccionamos a los diez autores que más publicaron en el Piso Salarial de la Enseñanza Pública de la Educación Básica y buscamos aprehender los resultados más destacados por estos autores en relación con la implementación del PSPN, creado por la Ley 11.738 , del 16 de julio de 2008.

Las personas, las autoridades educativas, los empresarios y especialmente los políticos hacen discursos elocuentes y adjetivos de reconocimiento al maestro, pero la práctica es descaradamente contradictoria.

\section{PISO SALARIAL Y REMUNERACIÓN DOCENTE: UNA REVISIÓN DE LA LITERATURA}

Cómo se contextualiza anteriormente, el objeto de este trabajo es la implementación del piso salarial de los docentes, sobre el cual presentamos esta revisión bibliográfica. Con este fin, la metodología desarrollada para la búsqueda bibliográfica se basa en el uso científico y cuidadoso de la teoría de la Evidence-based practice (EBP).

RC: 101661

Disponible: https://www.nucleodoconhecimento.com.br/educacion-es/remuneraciondocente 
Cabe destacar aquí que la discusión sobre las búsquedas bibliográficas basadas en la evidencia nace de los estudios de la Medicina Basada en la Evidencia (EB) y se expande a otras disciplinas con el término PBE. Según Santos et al. (2007),

a PBE prevê metodologias e processos para a identificação de evidências de que um certo tratamento, ou meio diagnóstico, é efetivo, estratégias para avaliação da qualidade dos estudos e mecanismos para a implementação na assistência. (...) O movimento da PBE teve origem simultânea na McMaster University (Ontario, Canadá) e na University of York (Reino Unido). Evidência é aquilo que é claro, a constatação de uma verdade que não suscita qualquer dúvida. Evidência científica representa uma prova de que um determinado conhecimento é verdadeiro ou falso. Para que se tenha evidência científica é necessário que exista pesquisa prévia, conduzida dentro dos preceitos científicos (SANTOS et al., 2007).

En este sentido, la propuesta fue realizar una búsqueda bibliográfica basada en preceptos científicos con el objetivo de extraer del objeto principal "pago del Piso Salarial Profesional Nacional - PSPN", el trabajo de investigación más correlacionado e importante para su estudio.

Además, justificamos la adopción de esta metodología porque existen críticas a las revisiones de las literaturas tradicionales, que no cuentan con metodologías específicas y explícitas, demostrando así total aleatoriedad y sesgo en sus búsquedas. Santos et al. ( 2007) trae a colación esta discusión cuando expone que:

As revisões de literatura tradicionais (hoje chamadas revisões narrativas) há muito são criticadas, uma vez que o método de busca bibliográfica e seleção dos estudos não são padronizados e explicitados. Os resultados obtidos com tais revisões são tendenciosos, não esgotam toda a literatura disponível sobre o tema pesquisado e geralmente são inconclusivos. A busca de evidência requer adequada definição da pergunta de pesquisa e criação de estrutura lógica para a busca bibliográfica de evidências na literatura, que facilitam e maximizam o alcance da pesquisa (SANTOS et al., 2007).

Según Bariani et al. (2007), para las búsquedas bibliográficas basadas en la evidencia, se deben seguir algunas pautas, como lo hicimos en este trabajo:

RC: 101661

Disponible: https://www.nucleodoconhecimento.com.br/educacion-es/remuneraciondocente 
I. Las búsquedas bibliográficas hoy en día se realizan en gran medida en directorios en línea, es decir, en bases de datos en línea. Para este trabajo, realizamos una búsqueda en la base de datos de Capes, Scientific Electronic Library Online - Scielo, Google Scholar y Google Books.

II. Selección de descriptores, o palabras clave, alineados con las especificidades del tema. De esta manera, evitamos búsquedas con descriptores amplios y generalistas.

III. Delimitación de la tipicidad de las palabras clave, priorizando el uso de sustantivos y adjetivos; uso de palabras en singular $\mathrm{y}$, por último, evitar preposiciones, conjunciones o artículos.

IV. Verificación y validación de las palabras elegidas en los sitios de publicación en las principales áreas de estudio relacionadas con la investigación.

V. Filtrado de búsqueda. La búsqueda debe estar bien delimitada, por lo que hay algunas formas que se siguieron en esta búsqueda:

A) Búsqueda del material en el marco temporal de la investigación;

B) Búsqueda exacta de términos. La búsqueda exacta se facilita cuando las palabras

o frases se escriben entre comillas;

C) Uso de operadores lógicos booleanos AND, OR y NOT, cuándo AND se utiliza para ubicar más de un término en la misma referencia; NOT excluir que se encuentre un término común con la palabra clave utilizada; y OR para excluir términos más comunes de ser encontrados con la palabra clave utilizada.

RC: 101661

Disponible: https://www.nucleodoconhecimento.com.br/educacion-es/remuneraciondocente 
Tabla 1 - Expresiones de búsqueda clave

\begin{tabular}{|l|l|}
\hline Piso salarial AND magisterio & PSPN AND magisterio \\
\hline $\begin{array}{l}\text { Salario mínimo AND educación } \\
\text { profesional }\end{array}$ & PSPN AND educación profesional \\
\hline $\begin{array}{l}\text { Piso salarial AND docente } \\
\text { Piso salarial AND docente }\end{array}$ & PSPN AND profesor \\
\hline $\begin{array}{l}\text { Piso salarial AND educador } \\
\text { Piso salarial AND educación de los }\end{array}$ & $\begin{array}{l}\text { PSPN AND trabajador de la } \\
\text { trabajadores }\end{array}$ \\
\hline $\begin{array}{l}\text { Piso salarial AND educación } \\
\text { educación }\end{array}$ \\
\hline
\end{tabular}

Fuente: Elaboración propia (2021).

A partir del tema Piso Salarial Profesional Nacional, se delimitaron los términos clave, que son Piso Salarial y PSPN. Las búsquedas se realizaron con el recorte desde el 1 de enero de 2008 hasta el 1 de enero de 2021 en modo "búsqueda avanzada" en el portal CAPES, Scielo, Google Scholar y Google Books. Los términos OR y AND se clasificaron como operadores booleanos. Se realizó la combinación de los términos con el fin de buscar en las bases de datos los términos: Piso salarial o PSPN, combinando la búsqueda con los sinónimos conceptuales sobre docentes. Además, vale la pena mencionar que las preposiciones "da" y "de" se eliminaron con el propósito de refinar la búsqueda.

Después de la búsqueda de literatura, se creó una base de datos con todos los artículos, tesis y libros encontrados. Para el montaje de la base de datos, se ignoraron los artículos repetidos, las publicaciones fuera del período muestreadas y que no se publicaron en portugués.

Con el fin de ampliar el conocimiento sobre la literatura nacional, nuestra investigación bibliográfica se basó en la búsqueda de artículos nacionales, monografías, tesis, disertaciones y libros que abordan, de manera contextualizada, 
el piso salarial. Este filtro fue elaborado a partir del título y resumen de artículos científicos, tesis, disertaciones, monografías y libros.

Los descriptores más eficientes fueron "salario y piso docente", "piso salarial y de educación profesional" y "piso salarial y maestro". El otro, "piso salarial y educador", "piso salarial y trabajador de la educación", "piso salarial y educación" devolvió, en conjunto, 12 resultados. Al final, la búsqueda totalizó 60 producciones bibliográficas a analizar.

Entre las fuentes de búsqueda utilizadas, Google Scholar y Google Books regresaron con un mayor volumen de datos. Por ello, se utilizó el criterio de clasificación por relevancia del contenido seguido de la selección de los diez primeros trabajos que contemplaron los criterios y objetivos de esta investigación. El plazo fue del 1 de enero de 2008 al 1 de enero de 2021, justificado por la fecha de inicio del piso y extendiéndose hasta el período de cambios en la Ley FUNDEB.

Reconocemos la limitación de los criterios de búsqueda, aunque entendemos que se trata de un esfuerzo por vincular la investigación y las discusiones en línea con el avance de las discusiones sobre el piso salarial nacional. Se descartaron artículos, noticias, producciones internacionales que no abordaron el salario mínimo en el contexto brasileño o que lo abordaron de manera marginal.

\section{PRODUCCIÓN BRASILEÑA Y SUS CARACTERÍSTICAS}

Si bien los enfoques y la consolidación de las políticas de apreciación docente han evolucionado desde hace décadas, es a partir de mediados de 2010 que la discusión en materia de piso salarial y remuneración docente gana mayor cuerpo, lo que refleja el crecimiento de las publicaciones, tanto en revistas científicas como en libros especializados.

A. Número de búsquedas a lo largo de los años

RC: 101661

Disponible: https://www.nucleodoconhecimento.com.br/educacion-es/remuneraciondocente 
A lo largo de los años, los debates sobre la Ley PSPN se han centralizado en la aplicación de la política. Al analizar las producciones a lo largo de 13 años, observamos un aumento en las publicaciones en los años 2016 y 2019, en comparación con los otros años de publicaciones. Hay un incremento en 2016, cuya posible correlación son las elecciones municipales y los cambios que podrían venir de las nuevas administraciones municipales. Otra posible subida en 2019 parece coincidir con el movimiento social y la articulación sobre el Fondo Nacional para el Desarrollo de la Educación - FUNDEB, que tenía, hasta ese momento, carácter provisional.

Figura 1 - Número de búsquedas a lo largo de los años

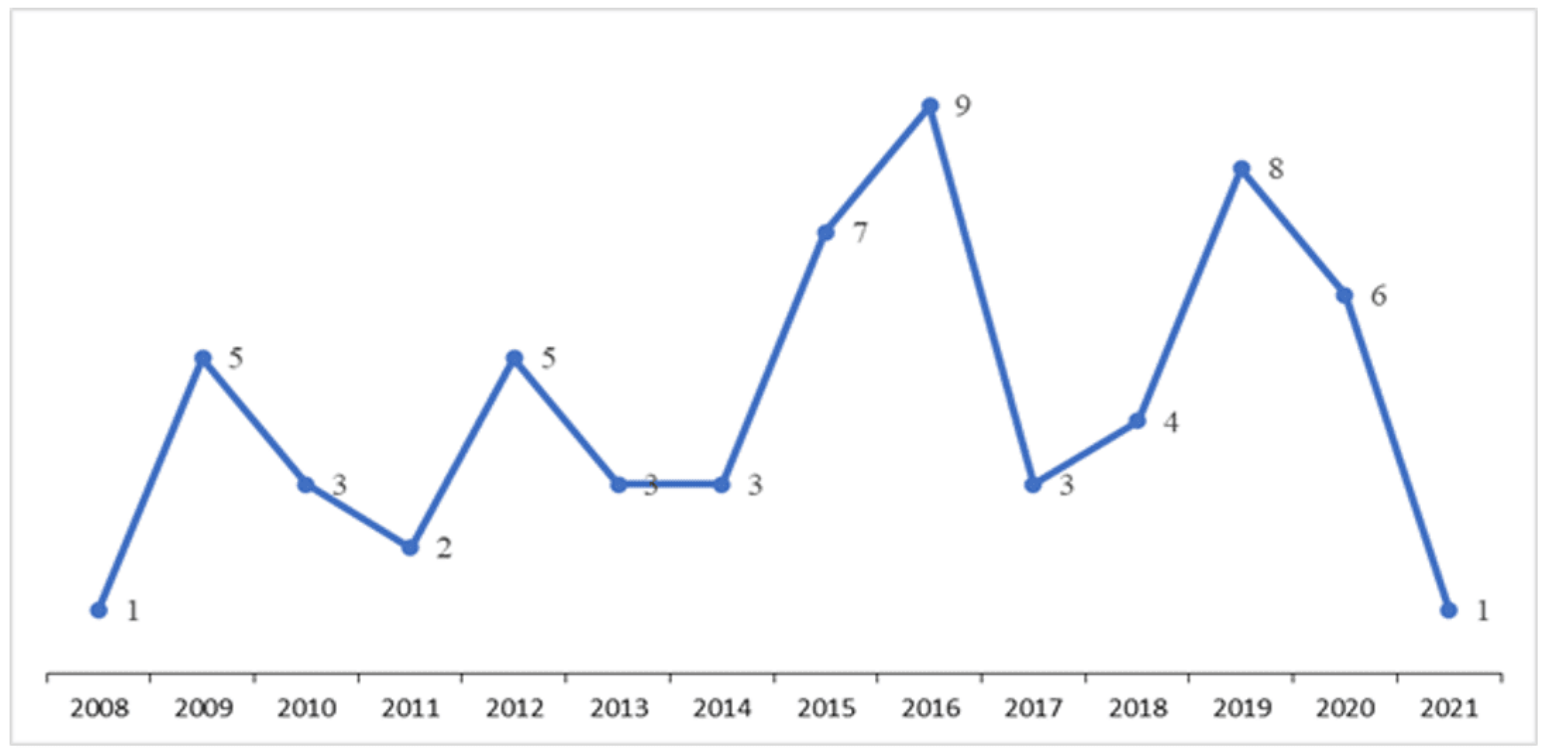

Fuente: Elaboración propia (2021).

B. Tipos de publicación

En general, el tipo de publicación predominante son los artículos y libros, representando el $86,7 \%$ del conjunto total de esta encuesta. Estos estudios fueron impulsados principalmente por producciones en el área de Educación. Tesis, disertaciones y monografías tuvieron baja representatividad en el conjunto total de esta encuesta en relación con artículos y libros.

RC: 101661

Disponible: https://www.nucleodoconhecimento.com.br/educacion-es/remuneraciondocente 
Gráfico 2 - Tipos de publicación

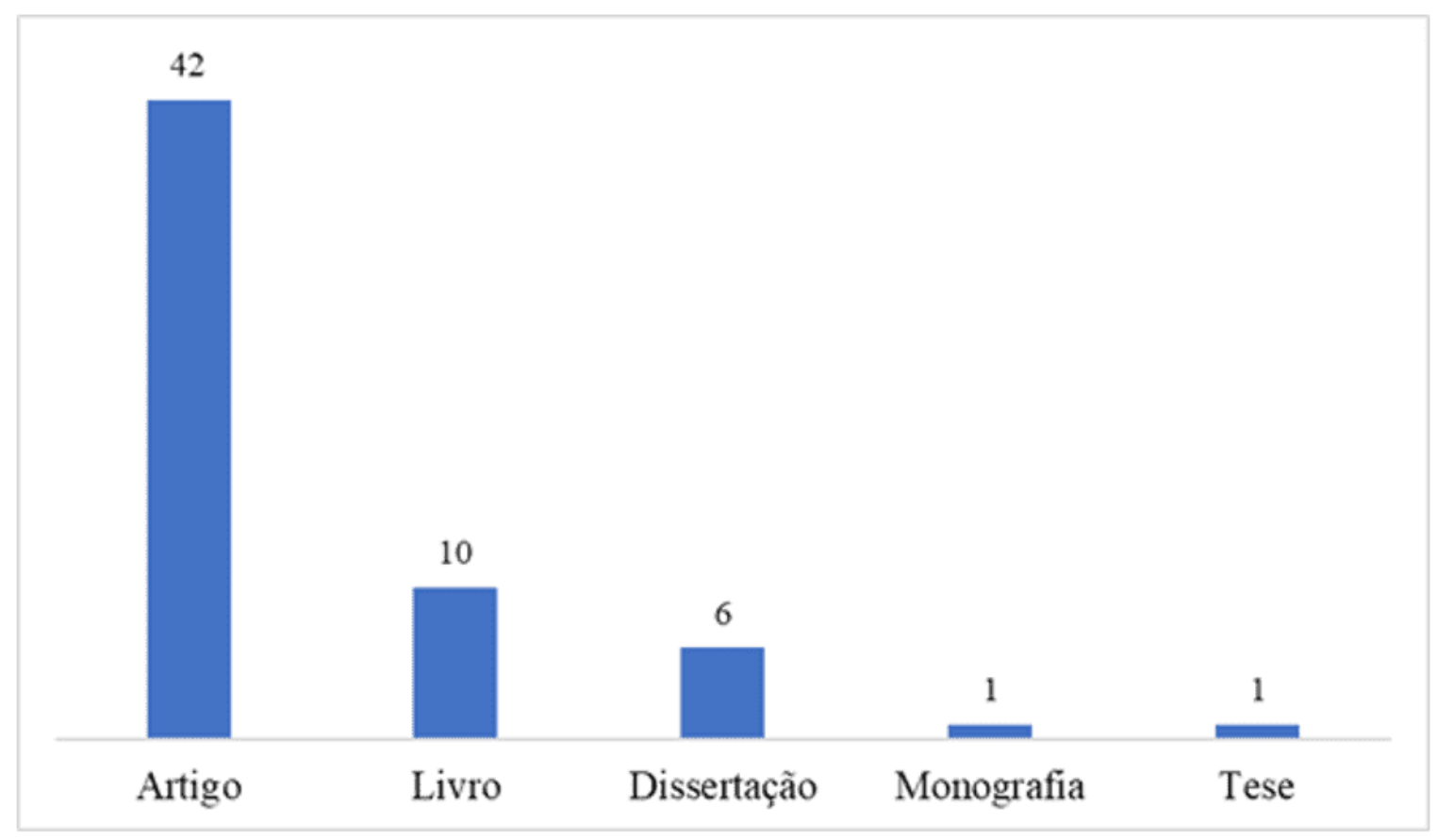

Fuente: Elaboración propia (2021).

C. Área editorial

La investigación académica en Brasil sobre el piso salarial se centra en el área de la educación, alcanzando la tasa del 80\% (48 publicaciones). Del total de publicaciones sobre piso salarial en el área de educación, 32 son artículos y 10 son libros. Por lo tanto, prevalece la producción de artículos y libros. Además, las áreas de Ciencias Sociales y Ciencias Políticas juntas representan el 11,7\% (7 publicaciones).

RC: 101661

Disponible: https://www.nucleodoconhecimento.com.br/educacion-es/remuneraciondocente 
Gráfico 3 - Áreas de publicación

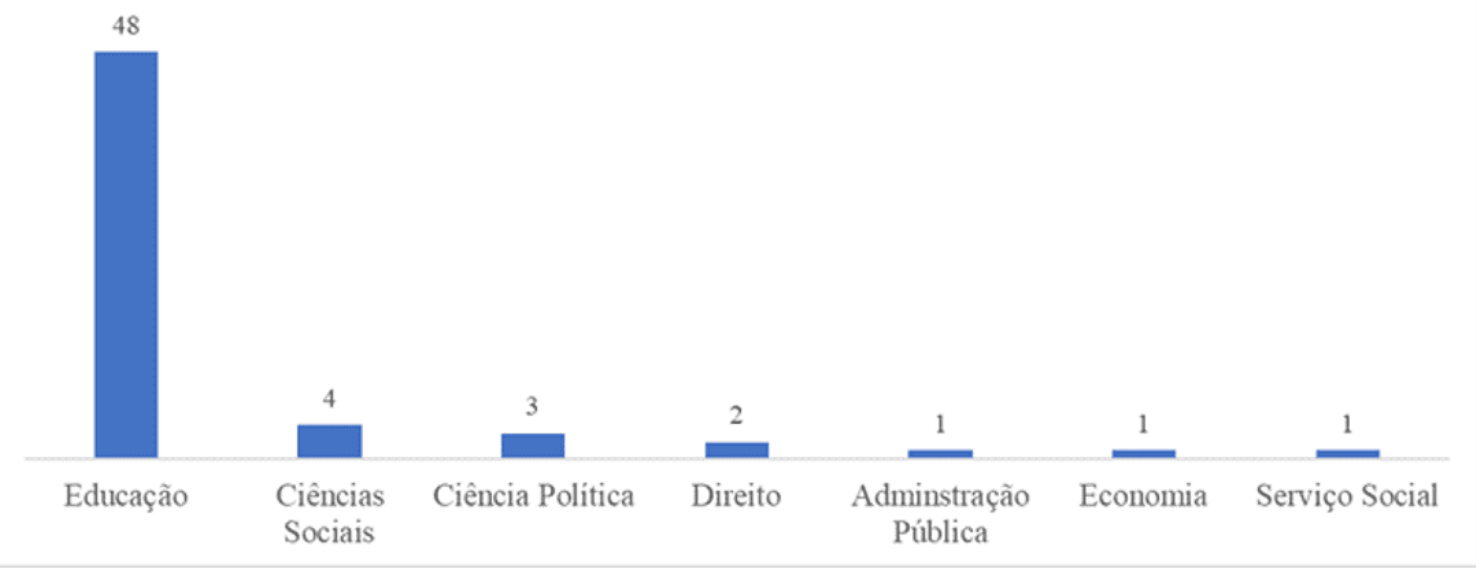

Fuente: Elaboración propia (2021).

Figura 4 - Áreas de publicación por tipo de publicación

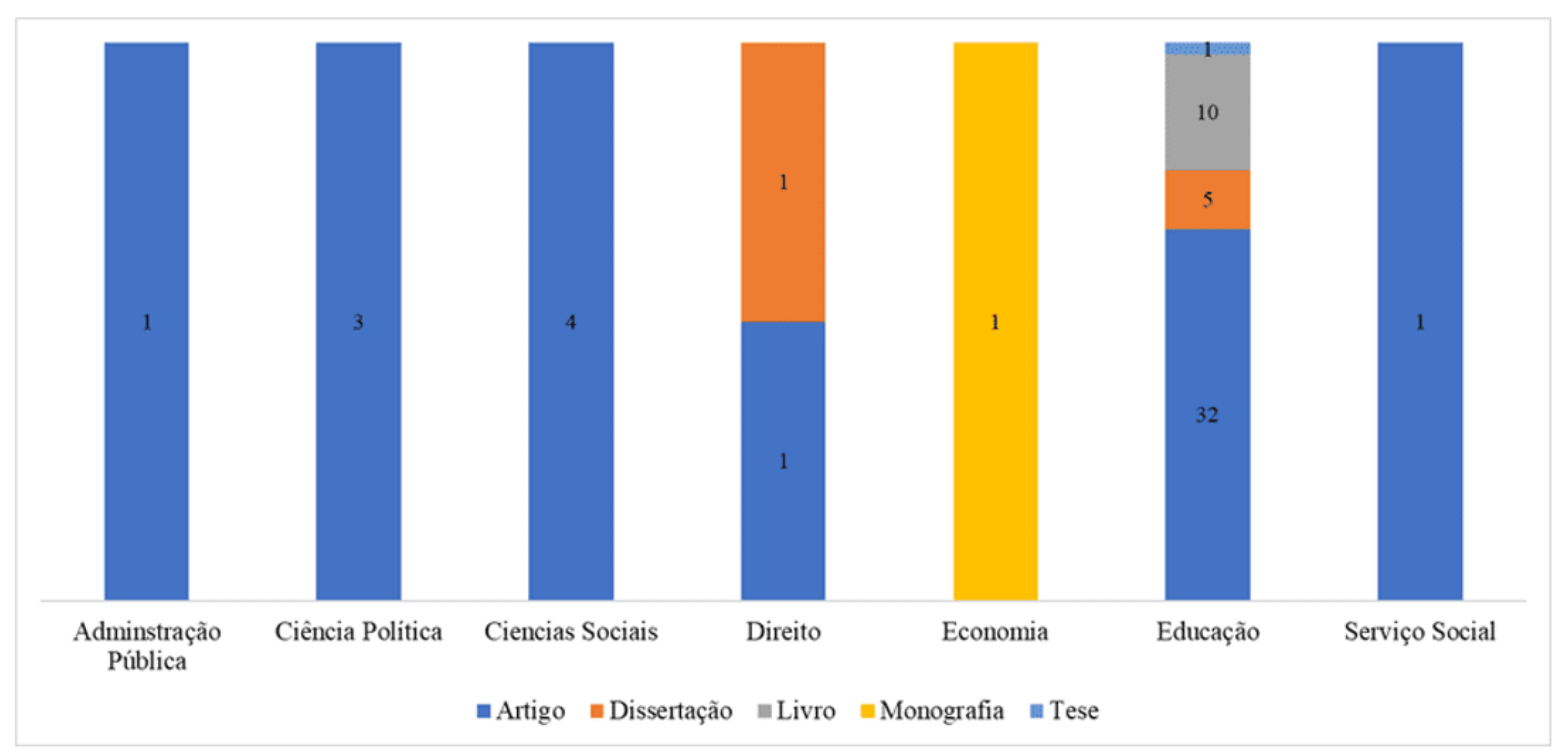

Fuente: Elaboración propia (2021).

D. Principales regiones de publicación

Ampliando el análisis de la producción académica nacional, observamos si los lugares de publicación de artículos, libros, etc. eran regionales o nacionales.

RC: 101661

Disponible: https://www.nucleodoconhecimento.com.br/educacion-es/remuneraciondocente 
Figura 5 - Regiones de publicación

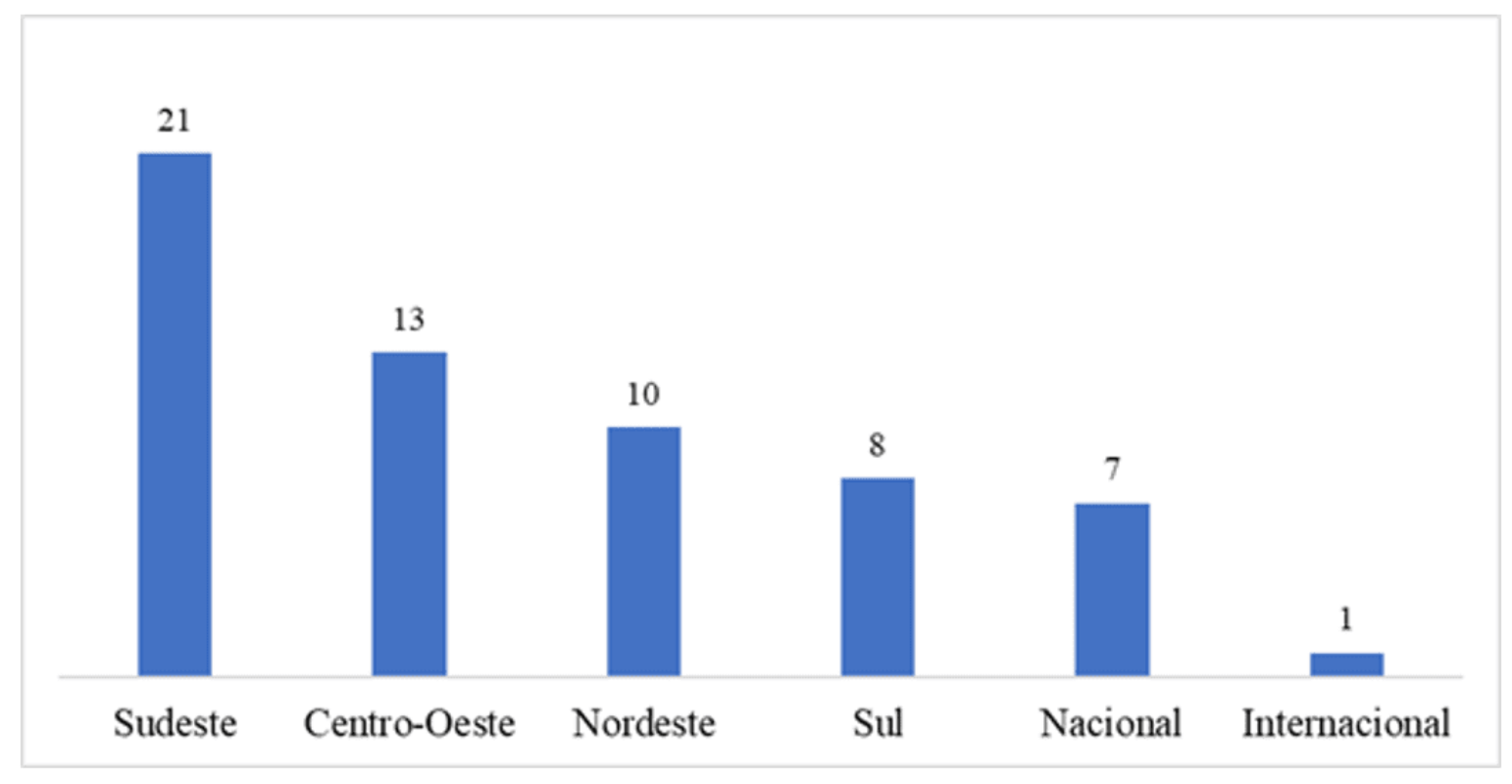

Fuente: Elaboración propia (2021).

La búsqueda bibliográfica indica la región Sureste del país como uno de los principales lugares de publicación. Además del carácter nacional, las regiones Medio Oeste, Noreste y Sur también preponderan, en orden decreciente.

E. Principales lugares de estudio de las publicaciones

RC: 101661

Disponible: https://www.nucleodoconhecimento.com.br/educacion-es/remuneraciondocente 
Gráfico 6 - Regiones de estudio de las publicaciones

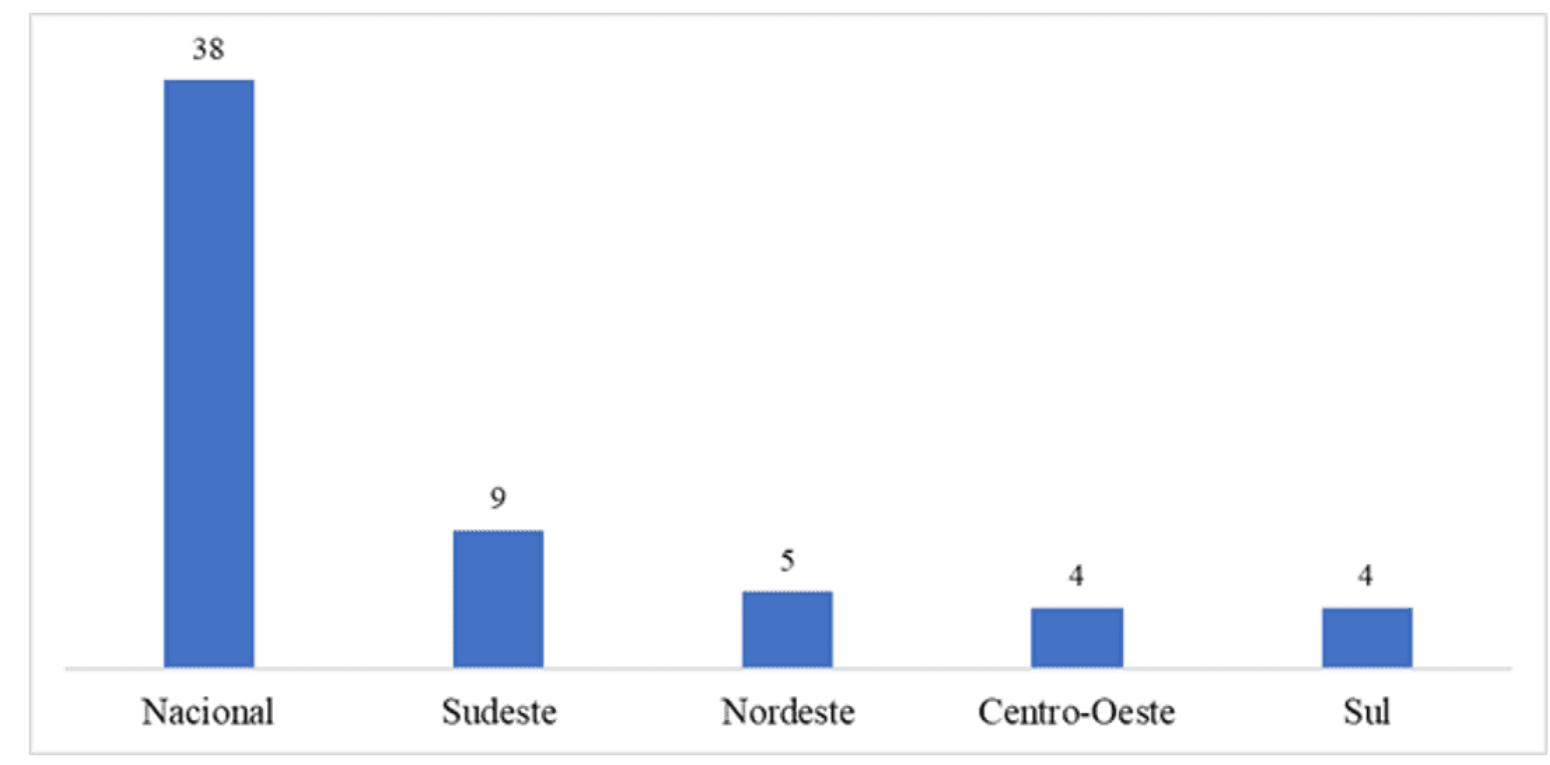

Fuente: Elaboración propia (2021).

Específicamente, analizando los títulos y resúmenes de las publicaciones, verificamos la tendencia de los estudios sobre la Ley PSPN a nivel nacional $(63,3 \%)$. Los análisis regionales comprenden alrededor del $36,7 \%$ de todas las publicaciones. La región Sudeste continúa como el foco de muchos estudios, y como hemos identificado, especialmente se destacan los estados de São Paulo y Minas Gerais. A continuación, surge la Región Nordeste, que representa el $8 \%$ en el conjunto total de publicaciones, y vale la pena mencionar los Estados de Bahía, Rio Grande do Norte y Piauí como el foco de análisis de estudios regionales sobre el piso salarial. 
Gráfico 7 - Estúdio de publicación UF

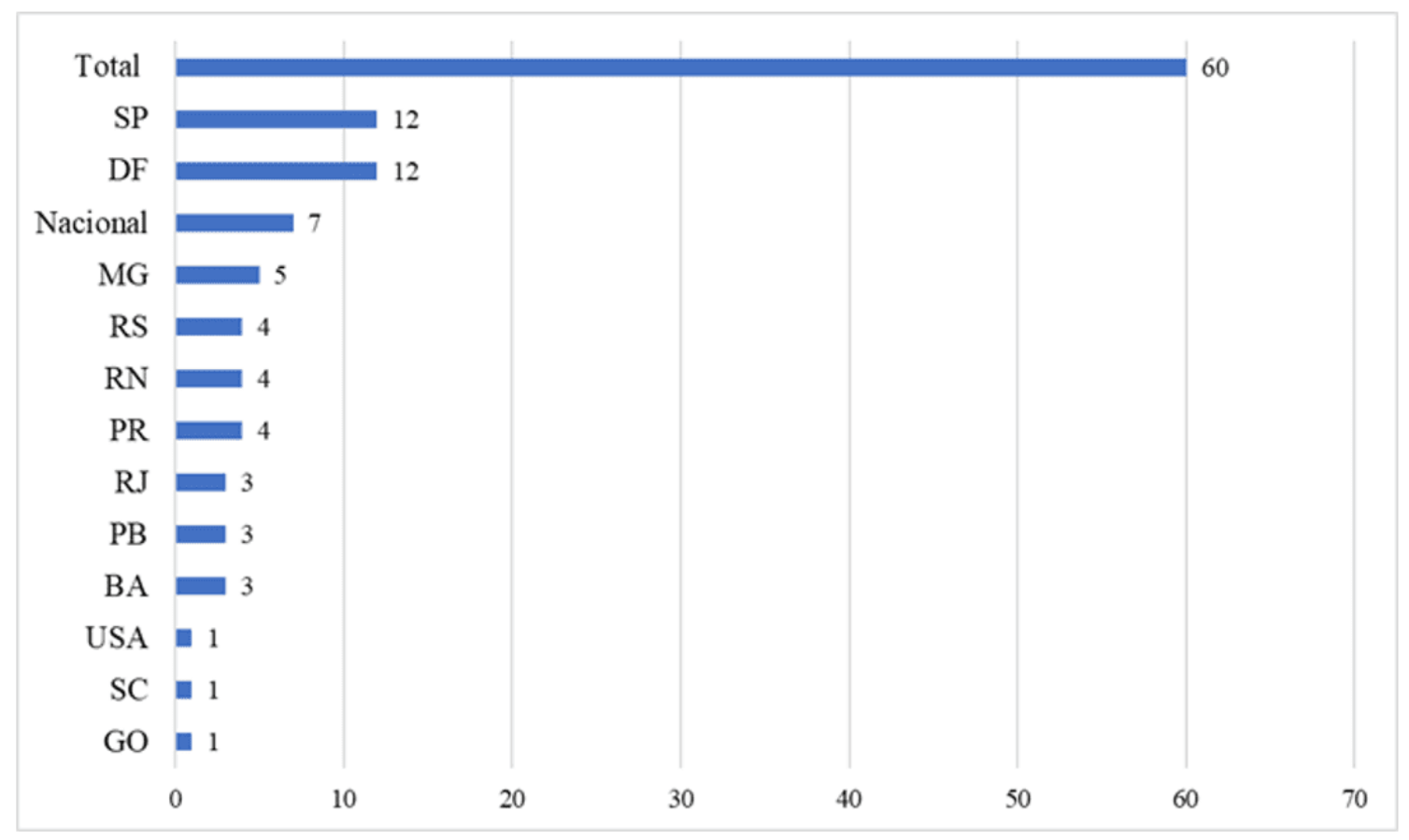

Fuente: Elaboración propia (2021).

F. Autores principales

A partir de la identificación de artículos, monografías, disertaciones, tesis y libros, fue posible levantar los nombres de los autores que los escribieron. Vale la pena mencionar que cuando la obra tenía coautoría, como en algunos libros específicos, se enumeraban los nombres de todos.

Luego se enumeraron y agruparon los autores para obtener el número de veces que un autor determinado publicó. Para ello, creamos una lista con estos autores y desarrollamos una nube de palabras para visualizar las más destacadas. La nube de palabras enfatiza, de manera directamente proporcional, la frecuencia de aparición de las palabras. Así, podemos observar que los diez autores con mayor número de publicaciones son: Maria Dilnéia Espíndola Fernandes, Andréa Barbosa Gouveia, Márcia Aparecida Jacomini, Claudio Pinto Nunes, Eliara Cristina Nogueira da Silva Teixeira, Ana Paula Santiago do Nascimento, Andreza Barbosa, Áurea de Carvalho

RC: 101661

Disponible: https://www.nucleodoconhecimento.com.br/educacion-es/remuneraciondocente 
Costa y Dalila Andrade Oliveira. La clasificación de los autores ayuda en la delimitación de los autores y la bibliografía sobre el piso salarial. Podemos ver que la autoría es predominantemente femenina.

Figura 1 - Autores principales

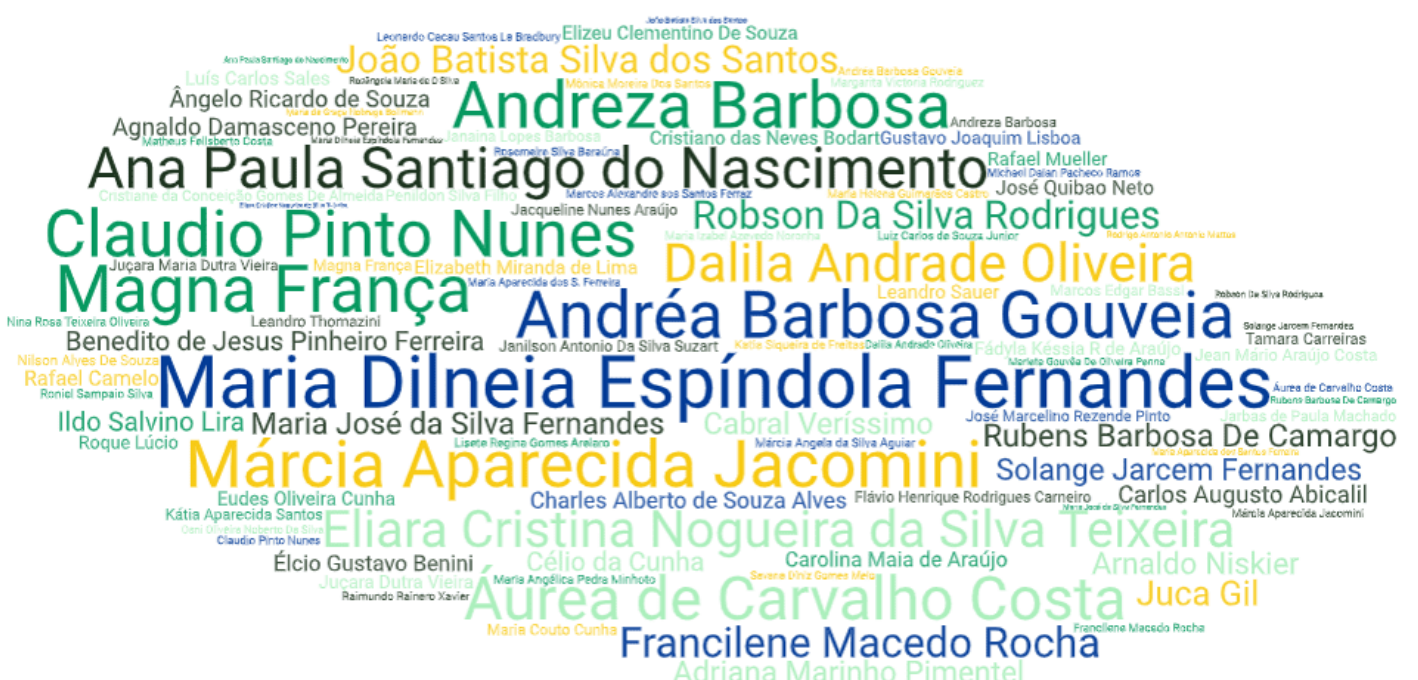

Fuente: Elaboración propia (2021).

\section{EL PISO SALARIAL PROFESIONAL NACIONAL Y LA APRECIACIÓN DE LOS MAESTROS: LO QUE DICEN LOS ACADÉMICOS}

La revisión bibliográfica tiene un carácter cualitativo y exploratorio y fue elaborada para apoyar los estudios de doctorado de este investigador sobre la implementación de la Ley 11.738/2008, que creó el Piso Nacional de Salario Profesional - PSPN. Para contextualizar la investigación, es importante que sepamos cómo se ha abordado el tema relacionado con la remuneración docente en las producciones académicas. Se trata de una investigación que inicialmente tuvo el único propósito de contextualizar, situar a los autores sobre la producción y las posiciones académicas, pero permitió comparar la producción de discursos en política educativa y la verificación de su aplicación práctica en el mundo académico. Para este trabajo, seleccionamos los diez artículos de autores que más producían en planta,

RC: 101661

Disponible: https://www.nucleodoconhecimento.com.br/educacion-es/remuneraciondocente 
remuneración docente y cumplimiento de la Ley PSPN, entre 2008 y 2021. Estos artículos abordan la remuneración de los maestros y sus relaciones con los fondos de financiación de la educación básica.

Después de todo, ¿qué dicen los académicos sobre el salario de los maestros, considerando que hubo casi dos siglos de luchas por el Piso Salarial Profesional Nacional?

El 15 de octubre de 1827, Don Pedro I estableció, en el art. 3 de la Ley de Escuelas de Primeras Letras, el primer piso salarial para el maestro, pero esto nunca se aplicó. Desde la Constitución de 1988, las discusiones sindicales y académicas han adquirido contornos cada vez más pronunciados. Pocos expertos en educación desvincularon la lucha por la democratización de la lucha por la escuela pública gratuita, con maestros con sólida formación inicial y salario digno. El 16 de julio de 2008, el entonces presidente Lula sancionó la Ley 11.738/2008, que estableció el Piso Salarial Profesional Nacional para los profesionales de la educación pública básica, estableciendo un valor que se ajustará obligatoriamente cada año y "por debajo del cual la Unión, los Estados, el Distrito Federal y los Municipios no podrán fijar el salario inicial de las Carreras de la enseñanza pública de la educación básica, para el viaje de un máximo de 40 (cuarenta) horas semanales" (BRASIL, 2008). Aunque el piso ha sido establecido por ley desde 2008, más de 10 años después de su sanción en más de la mitad de los municipios, más de la mitad de los municipios brasileños violan la Ley de Piso, sin ningún castigo.

Hubo dos siglos de luchas de los maestros por la creación del piso salarial para el magisterio, pero todavía hubo intentos de algunos gobernadores de evitar su sanción, que afortunadamente se vieron frustrados.

Durante un trabajo de consultoría realizado para UNESCO/MEC, encontramos que de 5.570 municipios, solo el 30\% cumplió con la Ley 11.738/2008 en su totalidad, es decir, pagando el piso inicial, creando nuevos planes de carrera, asegurando el $30 \%$ de la carga de trabajo para estudios y planificación, además de asegurar una sólida 
formación inicial e ingreso por licitación pública. Por lo tanto, decidimos estudiar la implementación del piso salarial, y en el caso de la tesis doctoral[4] que estamos desarrollando, especialmente sobre el estado de Bahía, que es el 4º estado más grande de la Federación y el más grande del Nordeste brasileño. Inicialmente, para apoyar los estudios de la tesis citada sobre la implementación del piso en los 417 municipios de Bahía, buscamos una base de investigación bibliográfica que alcanzara decenas de estudios. Para este artículo, presentamos a los diez autores que más produjeron sobre el tema en este período. En este contexto, el objetivo de este artículo es presentar el desarrollo de esta línea de investigación, que consideramos relevante. Destacamos sus temas centrales, sus avances y limitaciones, en definitiva, el estado del arte de la literatura sobre PSPN.

A pesar del dilema que implica las influencias de la política en las políticas públicas para los docentes y para la educación de calidad, en un país de "democracia restringida", como señaló Florestan Fernandes (1987, p. 160), insistimos en la búsqueda de preguntas que nos permitan identificar el lugar que ocupa la apreciación del docente y la formación en el universo académico. Para responder a la pregunta sobre el interés de los estudios realizados sobre la implementación del Piso Salarial Profesional Nacional - PSPN y si estos indican las repercusiones del piso salarial para la valorización del magisterio, en el periodo 2008-2021, se buscaron artículos, monografías, disertaciones y tesis en el área de Ciencias Sociales o el Área de Educación.

En los últimos cuarenta años, autores más importantes, aunque pocos, se han dedicado al análisis de los estatutos, programas y prácticas de los gerentes y han procurado comprender la influencia de los partidos políticos en la explicación de las variaciones en los resultados de las acciones gubernamentales en el área de la educación. En este periodo, sin duda, los estudios sobre prácticas y políticas educativas vienen incluyendo al docente, antes casi invisible. Prueba de ello fueron los capítulos de la Constitución Federal y las Constituciones Estatales que destacan la apreciación del maestro; la Ley de Lineamientos y Bases de la Educación Nacional; la definición de las Directrices Nacionales para la Formación Docente; los

RC: 101661

Disponible: https://www.nucleodoconhecimento.com.br/educacion-es/remuneraciondocente 
Planes Nacionales de Educación de Brasil - PNE (2011-2020) y PNE (2014-2024) y la Ley 11.738/2008, que creó el piso salarial, documentos para los cuales la calidad de la educación y la apreciación de los docentes constituyen verdaderos desafíos. En el nuevo Plan Nacional de Educación de Brasil - PNE (2014-2024), de las 20 metas esbozadas, 4 se refieren al maestro, aunque los Planes Nacionales de Educación han sido dejados de lado por los gobernantes en las esferas federal, estatal y municipal, y se están transformando en meros protocolos de intenciones.

A continuación, pasamos a la investigación de los académicos sobre el PSPN, sobre su implementación, remuneración y apreciación del magisterio.

La Unesco ha publicado, en la última década, dos obras sin aliento: Professores do Brasil: impasses e desafios (2009), de Bernardete Angelina Gatti y Elba Siqueira de Sá Barretto, y Políticas Docentes - um estado da arte (2011), de Bernardete Angelina Gatti, Elba Siqueira de Sá Barretto y Marli Eliza Dalmazo Afonso de André. Estos estudios tienen una radiografía de los trabajadores de la educación. Professores do Brasil: impasses e desafios (2009) muestra la dimensión del desafío que es la valorización de los docentes y destaca que "los docentes se encuentran entre los grupos ocupacionales más numerosos". Y todavía existen "los desafíos de superar las conveniencias políticas y adoptar estrategias articuladas entre los diferentes organismos de formato". En conclusión, los autores utilizan la palabra "trama", que es un desafío teórico y está en el ámbito de nuestro trabajo. En 1992, publicamos la monografía titulada "A trama da ignorância" (LIMA, 1996), en la que analizamos discursos de las autoridades brasileñas sobre el maestro, en el Imperio y en la República, enfrentándose con las políticas efectivas de valorización del maestro. En 2011, las investigadoras Bernardete Angelina Gatti, Elba Siqueira de Sá Barretto y Marli Eliza Dalmazo Afonso de André publicaron el estudio Políticas Docentes no Brasil - um estado da arte, publicado por la UNESCO y de gran alcance. En este estudio, los autores mapean y analizan las políticas docentes aplicadas en los diferentes ámbitos federativos -Unión, Estados y Municipios- y sitúan en el centro de la discusión la formación inicial y continua del docente, la carrera docente y la evaluación de los docentes. En las conclusiones, se habla de la

RC: 101661

Disponible: https://www.nucleodoconhecimento.com.br/educacion-es/remuneraciondocente 
diversidad de propuestas para la apreciación docente, pero no se refieren a la plena implementación o no de la Ley 11.738/2008, que creó el Piso Salarial Profesional Nacional -PSPN-. Y advierten:

Se não houver aderência das propostas às políticas próprias dos estados e dos municípios, no caso das políticas federais, e destes últimos, no caso das políticas estaduais que a eles se estendem, ficam comprometidas a possibilidade de desenvolvimento profissional dos docentes e a sustentação das conquistas adquiridas (GATTI; BARRETO; ANDRÉ, 2011, p. 266).

El debate académico sobre la carrera y la remuneración docente fue objeto de investigación de los autores Rubens Barbosa de Camargo, Andréa Barbosa Gouveia, Juca Gil y Maria Angélica Pedra Minhoto (2009). En esta investigación, los autores analizan las relaciones entre los resultados del Fundef a partir de indicadores económicos y la remuneración docente, teniendo como parámetros las referencias legales sobre el Piso Salarial Profesional Nacional. Para ello, los autores utilizaron "indicadores económicos nacionales, salarios de los docentes en redes estatales y valores por año estudiantil de Fundef". Y concluyeron que las variaciones salariales están relacionadas con cada uno de los estados, presentando una inflexión positiva hacia la recomposición de los salarios, por encima de la inflación. Destacan la "necesidad de más estudios para comprender la dinámica de la remuneración". Sobre la necesidad de más estudios para apoyar la fijación del piso salarial, vale la pena preguntarse si los expertos olvidaron que los maestros esperaron dos siglos para conquistar el piso salarial establecido en la ley, para todo el país.

Para los autores, "la remuneración docente, además de tener que ser mejor 'descifrada', para dar el apoyo adecuado a la concepción de un PSPN, porque está determinada por factores (externos e internos) que involucran intereses diferentes" (CAMARGO et al., 2009). Todo ello "para exponer su mayor dimensión explicativa, revelándose como expresión concreta de una relación de fuerzas en disputa de proyectos de sociedad, de escuela, de hombre, de valorización de la enseñanza: en definitiva, como lucha política" (CAMARGO et al., 2009, p. 360). ¿Qué intereses son 
los que se trasladan a la no aplicación de la Ley que instituyó el piso salarial? ¿Se expresarán aquí las disputas sobre las cuales Florestan Fernandes, entre los escépticos de derecha o izquierda que ayudan poco, casi siempre sabotean la educación en Brasil?

En un artículo de 2010, Santiago do Nascimento, Amorim y Camargo (2010) analizaron la remuneración de los docentes en la red estatal de São Paulo al comienzo de su carrera y destacaron su composición basada en el documento del Departamento de Educación del Estado titulado Sistema de Informações Educacionais - Boletim de Acompanhamento de Pessoal (noviembre de 2010). Con ello, pudieron comprobar la evolución de los ajustes de pagos recibidos por los docentes, en el periodo comprendido entre 1996 y 2010.

Santiago do Nascimento, Amorim y Camargo (2010) encontraron que "la remuneración estaba compuesta por diferentes bonificaciones que representaban más del 35\% del total". Y que, en relación al salario mínimo, la retribución sufrió un aplanamiento, al pasar de 3,6 en 1996 a 2,4 en 2010. Los autores pretenden contribuir a las discusiones sobre la remuneración de los docentes en Brasil mediante el análisis de los períodos por parte de la gerencia, los gobernadores y / o los secretarios de educación. En la gestión del gobernador Mário Covas, la remuneración de los profesionales del PEB I pasó de $R \$ 360,94$ en 1996 a $R \$$ 710,00 en 2000 y 2001, en valores nominales. Comparando estos valores, notamos que la remuneración creció $96.71 \%$ en cinco años.

Bajo Alckmin, la remuneración de los profesionales de PEB I pasó de $R \$ 710,00$ en 2001 a R\$ 1.144,39 en 2005 (NASCIMENTO; AMORIM; CAMARGO, 2010). EI incremento fue del $61,18 \%$ en cuatro años. El vencimiento fue de $R \$ 610,00$ a $R \$$ 726,19 . Durante este período, se pagó el mayor porcentaje de bonificaciones, con bonificaciones que alcanzaron el $36,5 \%$ de la remuneración de los maestros.

Durante el período de gobierno de José Serra, los pagos iniciales de los maestros de PEB I pasaron de $R \$ 1.144,39$ en 2008 a $R \$ 1.198,16$ en 2010 , en valores 
nominales. Analizando los salarios ( $\mathrm{R} \$ 726,19$ y $\mathrm{R} \$ 981,88$ ), notamos un aumento del $35,21 \%$. La representatividad de las bonificaciones en el gobierno de Serra aumentó del $36,5 \%$ en 2008 al $18,1 \%$ en 2010 . Esto significa que este gobierno tenía una política de incorporar los bonos en el salario, pero con posible pérdida real de poder adquisitivo, de acuerdo a la relación con el salario mínimo. La representatividad de los bonos en el gobierno de Serra aumentó del 35,5\% en 2008 al $17,4 \%$ en 2010.

Así, los autores concluyen que a lo largo del período estudiado, cuando se toma como indicador el salario mínimo (o el salario necesario de Dieese), se percibió una fuerte oscilación. Sin embargo, cuando consideramos los años 1996 y 2010, notamos que había menos salarios mínimos, ya sea en salario o remuneración inicial, lo que indica un aplanamiento en los ingresos de los maestros de São Paulo.

Cuando se trata de la política de apreciación de los maestros, las tensiones son altas. En un artículo publicado por Maria Dilnéia Espíndola Fernandes y Margarita Victoria, con el título "O processo de elaboração da Lei ำ 11.738/2008, Lei do Piso Salarial Profissional Nacional para carreira e remuneração docente: trajetória, disputas e tensões", los autores rescatan la trayectoria reciente de la construcción de la Ley Nacional de Piso Salarial Profesional (PSPN) para la carrera y remuneración docente en Brasil, en el contexto de las reformas del Estado brasileño. Examinaron la ley federal, los documentos federales y sindicales, y la literatura sobre el tema. Destacaron una de las confrontaciones políticas más importantes en la construcción de las relaciones federativas brasileñas en ese momento histórico, que fue una Acción Directa de Inconstitucionalidad (Adin) contra la Ley № 11.738/2008, presentada por los gobernadores de los estados de Mato Grosso do Sul, Paraná, Santa Catarina, Rio Grande do Sul y Ceará. En la Acción Directa de Inconstitucionalidad, los gobernadores cuestionaron el piso salarial nacional de los maestros de enseñanza primaria pública, establecido por la Ley Federal 11.738/2008, discutiendo el alcance de la expresión "piso" (art. 2, caput y $\S 1 \%$ ); la limitación de la cantidad pagada como salario base inicial de la carrera o la extensión al salario general; y la configuración de la carga de trabajo. Y alegaron la RC: 101661

Disponible: https://www.nucleodoconhecimento.com.br/educacion-es/remuneraciondocente 
violación de la ley de reserva de iniciativa del Jefe del Ejecutivo para disponer del régimen jurídico del servidor público (art. $61, \S 1$, ii, c de la Constitución); contrario al pacto federativo (art. 60 , § 4 y punto de la constitución); incumplimiento de la regla de proporcionalidad: la jornada laboral y el salario establecidos por la ley. Los autores entendieron "que la PSPN se implanta en términos de concepción". Con el Supremo Tribunal Federal, máximo órgano jurídico del país, aprobado por la Ley № 11.738/2008 (BRASIL, 2008a), se resolvió la controversia legal, dando ganancia a los docentes, asegurándose planes de carrera para la docencia pública, piso salarial profesional y asignación del $30 \%$ de la carga de trabajo para estudios y planificación, además de ingresar a la carrera exclusivamente por concurso público de pruebas y títulos. El 17 de diciembre de 2008, en la votación del ministro Joaquim Barbosa se escribió que "no es creíble suponer que los estados federados se oponen a la reducción de las desigualdades regionales, con la mejora de las condiciones bajo las cuales se prestan los servicios de educación pública". La implementación del piso en las diversas unidades subnacionales ha demostrado lo difícil que es superar los localismos de la tradición cultural brasileña en la construcción histórica del federalismo. Para ellos, la viabilidad material del PSPN también dependerá de mucho esfuerzo por parte de los docentes de educación básica, así como de posibles alineamientos en las relaciones políticas en torno al modelo federativa vigente. El escenario nacional presenta situaciones muy diferentes en el tratamiento del tema salarial de los profesionales de la educación básica. Lo que tiene en común entre las unidades federadas sobre los salarios de los maestros es el bajo salario del maestro.

La especialista Dalila Andrade (2013) publicó el estudio titulado "As políticas de formação e a crise da profissionalização docente: por onde passa a valorização", en el que analiza la formación docente y la relación con la profesionalización. En el artículo, el autor busca comprender cuáles son los factores que determinan la mejora de la educación. Critica "ciertos enfoques que sitúan al docente como el principal responsable de la tarea educativa y, en consecuencia, de sus resultados, 
desplazando el foco de las estructuras y relaciones sociales que involucran el contexto escolar" (ANDRADE, 2013, p. 51).

Para Andrade (2013, p. 51), "la institución de la Ley Nacional de Piso Salarial Profesional y la creación de PARFOR son algunas de las políticas orientadas a una mayor apreciación docente". En esta investigación, el autor "busca discutir algunas correlaciones entre la educación inicial y la educación continua con remuneración, en un intento de resaltar sus relaciones para una mayor apreciación docente" (ANDRADE, 2013, p. 51). Y concluye que las políticas educativas actuales tienen como objetivo satisfacer las demandas de una mayor apreciación docente. Después de LDB 9394/96, el nivel de educación de los maestros ha aumentado significativamente. Sin embargo, la legislación fue enmendada permitiendo que el maestro con educación secundaria se convierta, en algunas entidades federativas, en una regla y no en una excepción. En esto el autor observa un retroceso en el plan legal. Concluye, con cierta aprensión, mostrando preocupación por una desviación de los pilares de las políticas: carrera; condiciones de trabajo y remuneración, con un posible cambio "hacia un modelo de responsabilidad de los docentes por su formación, especialmente la continuada, como forma de crecimiento individual y profesional" (ANDRADE, 2013, p. 69). "Existe una sensación general de que la profesión docente sufre un proceso de devaluación" (ANDRADE, 2013, p. 51). El análisis de los datos de la investigación mostró que la correlación entre la educación inicial superior (titulación) y la remuneración es segura. A diferencia de la educación continua, que no presenta una correlación segura. Esto propone repensar las políticas de educación continua. El autor señala que enfrentar la crisis de la carrera docente requiere de medidas efectivas para fortalecer la carrera, tanto en las formas de ingreso como en la permanencia del docente, en la carrera, lo que presupone condiciones de trabajo y remuneración.

Vemos que las políticas educativas actuales deben buscar una articulación entre las políticas formativas y las condiciones de profesionalización, dando mayor peso a una sólida formación inicial en la definición y certificación de la profesión. La exministra de Educación Rossieli Soares, del gobierno del presidente Michel Temer, presentó, RC: 101661

Disponible: https://www.nucleodoconhecimento.com.br/educacion-es/remuneraciondocente 
en el Senado Federal, el 15 de mayo de 2018, un documento titulado "Panorama da Educação Brasileira". En el documento, el MEC declaró 57 millones de inscripciones en la red pública, pero denunció la muy baja calidad de la educación pública, señalando entre las causas el alto porcentaje de docentes con capacitación inadecuada, que oscila entre el $30 \%$ y el $40 \%$. Y la mitad de los profesores de matemáticas no tenían formación en el campo. El exministro también informó que el $80 \%$ de los maestros de educación básica se forman en instituciones privadas. En los cursos de pedagogía, de las 690.780 matrículas, el $80 \%$ de ellas son en la red privada. Según Rossieli, las universidades federales deben entender que la formación docente es una estrategia nacional de desarrollo.

La investigadora Maria Dilnéia Espíndola Fernandes (2013), en el artículo "A valorização dos profissionais da educação básica no contexto das relações federativo brasileiro", analisa, desde instrumentos legales y legales, la valorización de los profesionales de la educación básica a través de la implementación del Fundeb y el Piso Salarial Profesional Nacional (PSPN) en el contexto de las relaciones federativas brasileñas. Después de realizar una investigación documental y revisar la literatura sobre el tema, a. El autor encontró que en las relaciones federativas brasileñas, las políticas educativas podrían contribuir a la colaboración federativa con respecto a la reducción de las desigualdades sociales. El autor concluyó que "el ejercicio del poder local sigue siendo a menudo un obstáculo para la coordinación federativa en materia de política educativa" y esto "determinaría el fuerte poder inductor de la Unión frente, entre otras situaciones, a la implementación del PSPN" (FERNANDES, 2013).

En 2016, Andreza Barbosa y Maria José da Silva Fernandes, en el artículo titulado "Piso Salarial em São Paulo: desvalorização dos professores", publicado en la revista Retratos da Escola, discutieron la situación actual de los salarios y las horas de trabajo de los docentes en la red pública estatal en el Estado de São Paulo para verificar la adecuación a la Ley № 11.738, 2008, que creó el piso salarial del magisterio. Los autores identificaron varias evidencias que revelan "que el gobierno estatal elude sistemáticamente la legislación federal, de acuerdo con la ley de horas RC: 101661

Disponible: https://www.nucleodoconhecimento.com.br/educacion-es/remuneraciondocente 
de trabajo de los maestros a la ley de piso, y pagando, ese año, una remuneración por debajo de la legalmente establecida, lo que aumenta la devaluación de los maestros" (BARBOSA; FERNANDES, 2016, p. 243).

El trabajo de investigación titulado "Financiamento da Educação e Luta Sindical: conflitos em uma grande rede de ensino", de Andréa Barbosa Gouveia y Marcos Alexandre dos Santos Ferraz, centrado en el impacto de la ley nacional de piso salarial profesional en las disputas de los maestros en Curitiba con el gerente de la red escolar local, analizó las agendas de reclamos del Sindicato de Maestros entre 2008 y 2012. Los autores centraron su enfoque en los ítems relacionados con el piso y la remuneración y la implementación de la actividad de 1/3 hora. Fue posible observar diferentes formas de vocalizar las demandas del piso y diferentes impactos concretos en la remuneración. En determinados momentos, provocando aplanamiento de la carrera y, en otros, aplanamiento del propio piso. En cuanto a la actividad de la hora, esta deja de ser un reclamo de organización del trabajo y asume la característica de un derecho justo. Los autores concluyeron que la forma en que se construyeron las agendas de reclamos cambió después del reajuste del piso, y que, a partir de 2012, "después de cambiar la forma de explicar el reclamo del piso, el índice de ajuste comienza a centrarse en toda la tabla salarial, sin distinción. Por lo tanto, el efecto de aplanamiento de la carrera está contenido", y que la implementación de la actividad de $1 / 3$ de hora se convierte en un tema importante, llamativo en las afirmaciones. En las agendas anteriores a 2011, el tiempo de actividad se limitaba a ser una agenda de seguimiento del cumplimiento de la legislación municipal ya vigente. Hasta 2011, las demandas de ajuste salarial seguían la lógica de sumar un conjunto de índices porcentuales: índice de inflación del período, índice de ganancia real, índice de pérdida histórica. Y hasta 2011, el ajuste del nivel 1 de la carrera (es decir, el piso) siempre se comportó de manera diferente a otros niveles. Es decir, el piso para el docente graduado es superior al que ocurre en los demás puntos de la tabla salarial (excepción hecha al año 2010). Esto significa que ha habido apreciación del piso, pero con aplanamiento de la carrera. Lo interesante es que en la suma de los años 2009, 2010 y 2011, el nivel 1 
de la carrera tiene un ajuste superior al ajuste del piso nacional en el mismo período. A partir de 2012, este concepto de sumar múltiples índices se reemplaza por un solo valor nominal de piso. El efecto de estas dos estrategias distintas es diferente cuando se observa el resultado final de las negociaciones. Los autores también concluyen que la agenda gana la dimensión de reclamar un derecho prescrito por la ley y concluyen afirmando: "el caso específico de la Red Municipal de Curitiba y SISMMAC muestra que los maestros están en continua evaluación de sus efectos, así como reevaluando sus propias tácticas y estrategias de lucha para poder disfrutar de un derecho que la sociedad brasileña les ha otorgado como justo" (GOUVEIA; FERRAZ, 2016).

Uno de los artículos más interesantes fue publicado en 2016 en la revista Proposições, con el título "Análise da carreira docente e valorização do magistério: condições de trabalho e desenvolvimento profissional", escrito por dos académicos que están en la lista de los diez autores que más publicaron sobre la valorización del magisterio, Márcia Aparecida Jacomini y Marieta Gouvêa de Oliveira Penna. Los autores abordaron varios aspectos relacionados con las condiciones de trabajo de los docentes de educación básica en Brasil y su desarrollo profesional, utilizando datos de la investigación "Remuneração de professores de escolas públicas de educação básica: configurações, impasses, impactos e perspectivas", realizada en 12 estados brasileños y sus capitales. Después de analizar los planes de carrera, verificar la capacitación requerida para la admisión, las horas de trabajo, los incentivos para la educación continua y la progresión profesional, los autores afirman que "a pesar de la importancia de los maestros para la promoción de una educación de calidad, aún deben abordarse varios problemas para garantizar condiciones de trabajo efectivas para los maestros" (JACOMINI; PENNA, 2016). Los autores concluyen el artículo citando una investigación sobre el estado docente en países como Argentina, Brasil, Perú y Uruguay, de Emílio Fanfani (2007, apud JACOMINI; PENNA, 2016), en el que señala que

toda política docente deve ser integral. Isto quer dizer que deve contemplar intervenções articuladas em pelo menos três dimensões:

RC: 101661

Disponible: https://www.nucleodoconhecimento.com.br/educacion-es/remuneraciondocente 
o recrutamento e a formação inicial e permanente, as condições de trabalho (divisão do trabalho pedagógico, carreira, contexto institucional, de trabalho, etc. e o sistema de estímulo e recompensa $s$ materiais e simbólicas (salário e reconhecimento social).

En otro párrafo de las consideraciones finales, los autores antes mencionados concluyen que "la investigación presentada en Brasil sobre las condiciones de trabajo del docente indica una devaluación política y social de la enseñanza que estructura dicha práctica profesional". Y afirman, sin entrar en los méritos, que "el docente debe tener el salario acorde con el valor e importancia que estos profesionales tienen en la sociedad contemporánea". La investigación indica la devaluación docente con la sociedad contemporánea y que para cambiar esta situación, es necesario reconocer y valorar la sociedad.

El análisis de "Intencionalidades das políticas de valorização docente que foram efetivadas nos governos FHC e LULA, a partir das políticas de Fundos (Fundef e Fundeb)" fue objeto de un estudio publicado por Teixeira y Nunes (2016). En este artículo, los autores examinan el tema salarial y de carrera de los docentes de educación básica a través del análisis del lugar ocupado por el Piso Nacional de Salario Profesional (PSPN) en las agendas de los gobiernos de FHC y Lula. También verificaron si las políticas aplicadas por estos gobiernos contribuyeron a la mejora salarial de los docentes brasileños. $Y$ concluyen que el piso salarial nacional como medida de valorización del magisterio recibió diferentes enfoques en los gobiernos de FHC y Lula. El Fundef, en el gobierno de la FHC, si bien provocó una mejora en los salarios de los educadores, resintió "un referente nacional para el inicio de una carrera, lo que provocó que este Fondo no lograra su objetivo de valorar la enseñanza de la educación básica". Por otro lado, fundeb, en el gobierno de Lula, además de mantener un mínimo del $60 \%$ de los recursos para el pago de los maestros, instituyó el período de un año para la creación del Piso Salarial en una ley específica, que culminó en la Ley № 11.738/2008, que estableció la implementación del Plan de Posiciones (TEIXEIRA; NUNES, 2016, p. 252).

RC: 101661

Disponible: https://www.nucleodoconhecimento.com.br/educacion-es/remuneraciondocente 
En un artículo de Robson da Silva Rodrigues y Áurea de Carvalho Costa (2019) titulado "Da Constituição Federal de 1988 ao Plano Nacional de Educação 2014 2024: ardilosas apropriações da noção de valorização do trabalho docente", los autores concluyen que las políticas implementadas entre 1988 y 2014 promovieron la devaluación del magisterio. La investigación tuvo como referencia teórica el materialismo histórico-dialéctico. Los autores dicen que al observar la actividad educativa en las prácticas diarias, "quienes implementan la práctica educativa contradicen las políticas educativas que decían apuntar a valorar a los docentes. Esta contradicción se deriva de la aplicación de nociones de valorización vaciadas de significado axiológico". En estos casos, así como en la legislación estatal, "el reconocimiento del valor del docente está relacionado con prescripciones externas sobre su trabajo y que se traiguen en recompensas en forma de remuneración, beneficios y progresión profesional, vinculadas a la cultura del desempeño" (RODRIGUES; CARVALHO, 2019, p. 231).

En un estudio realizado por Andréa Barbosa Gouveia y Maria Dilneia Espíndola Fernandes (2019), basado en datos reportados por la Lista Anual de Información Social (RAIS, 2016) sobre los salarios de los docentes en los estados de Mato Grosso do Sul y Paraná, se demostró que la implementación y mantenimiento del Piso Salarial Profesional Nacional se había debido a la inducción del Gobierno Federal y la consiguiente acción sindical. La agenda sindical docente incorporó la defensa del principio de valorización profesional y construyó la necesidad de un Piso Nacional de Salario Profesional (PSPN) como elemento estructurante. La regulación nacional de PSPN ocurrió en 2008; sin embargo, debido al pacto federativo brasileño, el cumplimiento de la legislación depende de los gobiernos locales. Esto implicó una amplia movilización de los sindicatos docentes para que la definición de remuneración incorporara la norma nacional. Para los autores, "el escenario de crisis institucional instalado en 2015, seguido de una agenda económica restrictiva para los derechos sociales, ha puesto en riesgo el conjunto de condiciones duramente ganadas para la valorización de los docentes" (GOUVEIA; FERNANDES, 2019, p. 89).

RC: 101661

Disponible: https://www.nucleodoconhecimento.com.br/educacion-es/remuneraciondocente 
En una investigación realizada en la Red Municipal de Educación de Belo Horizonte - RMEBH, las especialistas Francilene Macedo Rocha y Savana Diniz Gomes concluyeron que "la ley de PSPN, a diferencia de la valorización del magisterio que recomendaba, indujo una disminución en la remuneración y restricción del horizonte de las luchas de los maestros por la carrera única de los maestros de RMEBH, conquistada en 1996" (ROCHA; MELO, 2019, p. 3). Para los autores, con la política de Salario Profesional Nacional Piso hubo un proceso de precariedad del trabajo docente en el RMEBH, a partir de la segmentación de la carrera docente en maestro de escuela primaria y maestro de educación infantil, lo que rompió la lógica de la carrera única de los maestros del RMEBH. Este artículo presenta una discusión sobre los cambios en la carrera y la remuneración de los maestros de la red de educación municipal de Belo Horizonte (RMEBH) a partir de 2003, con la creación del puesto de educador infantil (IE), y a partir de 2008, con el establecimiento de la ley nacional de piso salarial profesional (PSPN). El período encuestado fue de 2003 a 2016. Para el análisis, los investigadores tuvieron como referencia teórica a autores críticos clásicos, como Karl Marx y Friedrich Engels, y contemporáneos, como Oder dos Santos, João Bernardo y Ricardo Antunes, entre otros. Se basaron en bibliografía del área, en investigaciones documentales centradas en leyes nacionales y municipales sobre carrera y remuneración y publicaciones del Sindicato de Trabajadores de la Educación de la Red Pública Municipal de Belo Horizonte (Sind-REDE/BH).

El artículo "Remuneração docente: efeitos do Plano de Cargos, Carreira e Remuneração em contexto municipal", de Maria Dilnéia Espíndola Fernandes, Solange Jarcem Fernandes y Viviane Gregório de Campos (2016), publicado en la revista Ensaio: Avaliação e Políticas Públicas, fue elaborado a partir de un estudio de caso. En este estudio, los autores buscaron verificar el efecto producido por los Planes de Empleo, Carrera y Remuneración (PCCR) implementados en el municipio de Campo Grande, en el período de 1996 a 2016, en términos de remuneración salarial para un docente mayor de 20 años de carrera. El análisis de la evolución de la remuneración del docente se realizó a partir del examen de sus holerites, 
comparados con el PCCR y el salario mínimo. Los autores encontraron que hubo un impacto positivo en la remuneración de la profesión docente, con el PCCR municipal obligatorio, y que el grado y el tiempo de trabajo fueron importantes para la valorización del maestro. Sin embargo, el pago íntegro del PSPN (Piso Salarial Profesional Nacional) se mantuvo, sin embargo, en una historia en el municipio, que también debe garantizarse a través del PCCR.

\section{ALGUNAS CONSIDERACIONES}

La recopilación de artículos sobre la pertinencia de los estudios relativos a la plena implementación del Piso Nacional de Salario Profesional - PSPN para profesionales de la educación básica corroboran, en cierta medida, los resultados. Con respecto a la devaluación del docente y la comprensión del significado de evaluar las repercusiones del PSPN en su valorización, las conclusiones confirman los estudios que consideran modelos institucionales, demandas sociales, formas de gobierno, políticas partidarias y espectros político-ideológicos como influenciadores de resultados, aunque estas no son las únicas causas. Más importante que las características formales de las instituciones estatales y sociales es cómo una configuración institucional influye en las relaciones políticas.

La redemocratización del país, la construcción de un conjunto de leyes y la observación del funcionamiento de las instituciones transformaron el estudio de las políticas públicas. Esto es evidente cuando identificamos las variables institucionales formales o formales en el análisis de los factores determinantes de las políticas educativas, como el comportamiento del poder judicial; la observación de la estructura federativa, con sus obstáculos; localismos en contraposición a la política de colaboración federativa; y grupos de interés y choques de posiciones políticoideológicas que sabotean las políticas educativas. Del mismo modo, la cuestión institucional sirve para identificar similitudes entre las unidades de análisis, permitiendo el enfoque sólo en la variación de otras características deseadas, como partidos, elecciones y condiciones socioeconómicas de las entidades federativas.

RC: 101661

Disponible: https://www.nucleodoconhecimento.com.br/educacion-es/remuneraciondocente 
Observamos un número significativo de estados y municipios que aplican PSPN de acuerdo con sus intereses y demandas sociales, a menudo en incumplimiento de la ley. En resumen, la complejidad de las políticas partidistas nos impuso la necesidad de crear una variedad de modelos y teorías para analizar sus procesos y resultados, como quedó claro en las discusiones de cada artículo. Tales estrategias analíticas, en diferentes medidas, se complementan entre sí y, al mismo tiempo, corroboran el desarrollo conjunto e integral de este campo de investigación sobre políticas públicas para la educación, particularmente sobre la correlación entre la educación de calidad y la apreciación docente.

\section{G. Principales temas tratados}

La búsqueda bibliográfica incluyó la extracción de resúmenes de los textos y especialmente de las palabras clave de los artículos, monografías, disertaciones y tesis. Cuando se analizaron los libros, se eliminaron los principales temas de indización bibliográfica. Al aglutinar todos los temas tratados, generamos la frecuencia de cada palabra clave.

La siguiente nube de palabras le permite clasificar temas en seis temas más relevantes. Son: política educativa, trabajo docente, piso salarial, piso salarial profesional nacional, valorización de la docencia y remuneración docente, que sugieren una gran correlación con el objeto de estudio de este trabajo.

RC: 101661

Disponible: https://www.nucleodoconhecimento.com.br/educacion-es/remuneraciondocente 
Figura 2 - Palabras clave principales

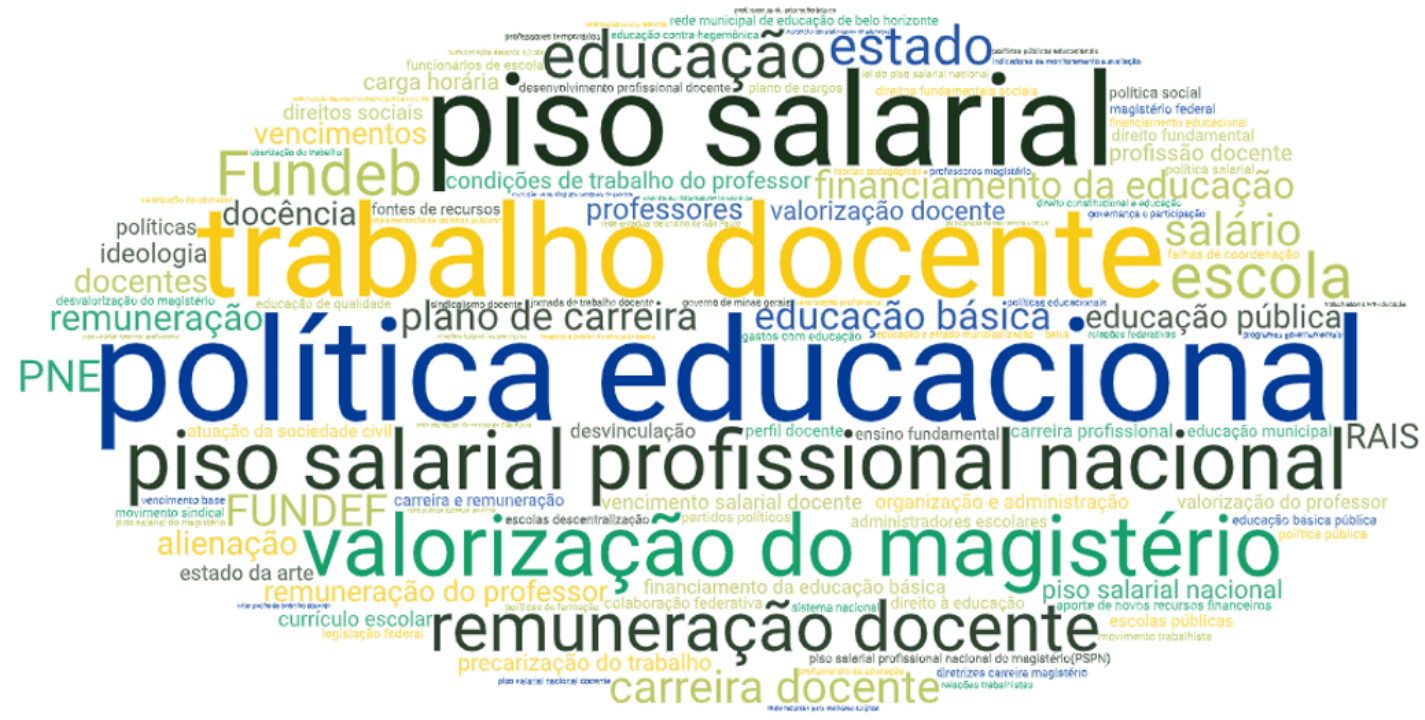

Fuente: Elaboración propia (2021).

En las que pesan tantas palabras de la nube que exaltan la política educativa, el trabajo docente, el piso salarial, el piso salarial profesional nacional, la apreciación de la enseñanza y la remuneración docente, estas palabras no parecen mantener la correlación esperada en la producción académica. Esto se debe a que no producen mayores impactos en la producción de un número significativo de tesis de maestría y doctorado, y estos estudios se concentran en artículos, o en indexaciones bibliográficas de libros.

En la experiencia de más de cuarenta años de militancia en el aula de educación primaria, media y superior, como líder sindical en el estado de Bahía, vicepresidente de la Confederación Nacional de Trabajadores de la Educación (CNTE), diputado estatal de 1991 a 1999, consultor legislativo en la Cámara de Representantes (1999 a 2003), Asesor Especial del Ministro de Educación (2003-2004), Asesor Especial de la Presidencia del INEP y Subsecretario de Educación Profesional del MEC - este investigador ha conocido empíricamente la tibieza de muchos expertos en educación y autoridades educativas, a la hora de defender salarios dignos para el docente. También conoció los impactos de esta concepción tan arraigada en la tradición

RC: 101661

Disponible: https://www.nucleodoconhecimento.com.br/educacion-es/remuneraciondocente 
cultural de Brasil en la producción académica poco significativa sobre el pago de salarios, como si se tratara de un tema menor.

En estas cuatro décadas de militancia en la educación, este autor conoció con consternación a dos reconocidos intelectuales brasileños que abogaban por una remuneración digna para el maestro: el sociólogo Florestan Fernandes y el filósofo Luiz Felipe Pondé. Florestan (1989, p. 58) consideró "la reducción salarial del maestro de primer grado la más perjudicial de todas". Y Florestan concluyó: "pocos países reducen al maestro de primer grado a una condición tan cercana a la miseria relativa como Brasil". Para él, "lo mismo ocurre con el profesor de secundaria, expuesto a una condición de inseguridad y baja retribución sin parangón. Estos grados de educación son pilares de la educación escolar". Y Felipe Pondé entrevistado por el periodista Thais Oyama, en el Programa Líneas Transversales de la Fundación Padre Anchieta (21/10/2021) denunció que "tratar la profesión del maestro y la educación como un tema idealizado, como un sacerdocio, es una estrategia para mantener al maestro pobre y feliz". El filósofo señala que "es necesario decir esto, porque en Brasil la condición de trabajo del maestro termina con la vida de cualquiera. Los salarios de los docentes se encuentran entre los peores del mundo" (PONDÉ, 2021).

Pondé destaca que "este tratamiento produce personas desanimadas; personas que sufren mucho para trabajar; personas que no tienen mucho horizonte" (PONDÉ, 2021). Por lo tanto, tan bueno como estar en la nube de palabras clasificadas, este debería ser un tema central en las tesis de maestría y tesis doctorales, no solo en el área de la educación, sino especialmente en el área de Derecho Público. Después de todo, no cumplir con la Ley de Piso es una transgresión inconmensurable de la ley; debe ser objeto de estudios de maestría y doctorado en ciencias sociales y políticas, ya que esto pone en tela de juicio la Política Nacional de Educación, la Constitución Federal y la Ley del Plan Nacional de Educación, consagrada por votos en el Congreso Nacional. Cabe señalar que no cumplir con la Ley de Piso representa un desmantelamiento de la Política Educativa, ya que 4 (cuatro) de las 20 metas del actual PNE se relacionan con la valorización del magisterio. Además, esto

RC: 101661

Disponible: https://www.nucleodoconhecimento.com.br/educacion-es/remuneraciondocente 
pone en tela de juicio los programas de los partidos, lo que perjudica realmente a la democracia.

Las palabras mágicas utilizadas para inhibir las discusiones, las afirmaciones y los estudios académicos sobre el salario de los maestros son: sacerdocio y corporativismo. Estas estrategias han estado funcionando secularmente.

Por lo tanto, este resultado de tales palabras expresivas, en la nube -en la que el piso salarial, el trabajo docente, la política educativa, el piso salarial nacional, el piso salarial nacional, la valorización de la enseñanza, la remuneración- no se articula con los resultados de las búsquedas sobre los números y tipos de publicación extraídos de los resúmenes de los textos, las palabras clave de los artículos, monografías, disertaciones y tesis y libros, de los cuales se eliminaron los principales temas de indización bibliográfica.

\section{CONSIDERACIONES FINALES}

Al llegar a esta última parte del estudio, elaboramos reflexiones y conclusiones sobre los Partidos Políticos y la implementación del piso salarial profesional nacional en los municipios - discurso y práctica. Se tomó un camino considerable en busca de la construcción de un marco teórico que permitiera no solo exponer la realidad de los docentes respecto a la implementación de la Ley № 11.738/2008, conocida como Ley Nacional de Piso Salarial Profesional - PSPN en su totalidad, en un plazo de menor tiempo (2008-2018). También buscamos exponer la contradicción entre los discursos de los políticos que incluyen en los estatutos y programas de partido la defensa del magisterio y el contraste de sus prácticas en el ejercicio del poder. La contradicción se configura entre los discursos grandilo hot de apreciación del maestro y las prácticas, a menudo degradantes.

En ningún período histórico, como en las últimas décadas, el papel del docente ha recibido tanto énfasis en los debates sobre los sistemas nacionales y las políticas 
educativas y por parte de diferentes actores, tanto públicos como privados, y organizaciones nacionales, internacionales y multilaterales.

La investigación demuestra la trayectoria de desajustes, peleas, derrotas y victorias que precedieron a la discusión y aprobación de la Ley № 11.738/2008. Asimismo, no sería posible sólo relacionar a las partes con el cumplimiento de la ley, sin demostrar el intrincado sistema político de partidos brasileño, desde sus orígenes.

La relevancia de este trabajo de investigación se muestra para evaluar los resultados de las políticas para la enseñanza y para el aumento de la calidad de la educación, especialmente en la última década. Cabe destacar que el Plan Nacional de Educación tiene cuatro de sus veinte metas directamente relacionadas con la valorización del magisterio. Y otros dos, que tienen repercusiones indirectas.

En esta perspectiva, la elección de este tema representó la posibilidad de evaluar la gestión pública de la educación y la confrontación de discursos y prácticas partidistas. En este sentido, se pudo constatar la aplicación efectiva de la política de valorización del magisterio a partir de una herramienta creada por el MEC con el objetivo de poner a disposición de los municipios instrumentos de información, seguimiento, evaluación y seguimiento de políticas para mejorar la calidad de la educación: el Plan de Acciones Articuladas - PAR/MEC.

Una primera conclusión es que, en la que tantas discusiones y énfasis en las políticas de valoración, con la cabeza la creación de una ley que establezca el piso salarial para la profesión docente, el alcance de la valoración efectiva del docente está lejos de lograrse.

El análisis en 417 municipios del Estado de Bahía, realizado con fines de investigación dirigidos a la elaboración de la tesis de este autor[5], nos permitió recopilar datos totales del mayor de los Estados del Nordeste de Brasil sobre la Implementación del Piso Salarial del Magisterio de Bahía, con relacionándolos con los Partidos Políticos por delante de los municipios. De los 417 municipios encuestados, incluidos los que no tienen partido, sólo 146 (35\%) cumplen RC: 101661

Disponible: https://www.nucleodoconhecimento.com.br/educacion-es/remuneraciondocente 
plenamente con la Ley 11.738/2008; y de los 271 restantes, hay $30(7,1 \%)$ que no dieron ninguna información. Así, se puede afirmar que 241 (57,7\%) municipios no cumplen a cabalidad con la Ley Nacional de Piso Salarial Profesional.

Aunque 180 municipios de Bahía afirman que pagan el valor del PSPN, esto no significa el pleno cumplimiento de la Ley, que solo tiene su pleno efecto legal si se articula al Piso Salarial, a la definición de al menos el 33\% del trabajo como horas de actividad (HA), y la garantía del Plan de Carrera. Cabe destacar la existencia de un solo municipio que declara no tener un Plan de Carrera, no cumplir con HA y no pagar el PSPN.

Una segunda conclusión importante, y las cifras lo demuestran, es que solo el 35\% de los municipios bahianos cumplen con la Ley Nacional de Nivel Salarial Profesional de los Profesionales de la Educación - PSPN, y casi el $60 \%$, más de la mitad de los municipios bahianos, no cumplen plenamente con la Ley 11.738/2008, después de 10 años de su sanción.

Posiblemente, el impago del piso se justifique porque la mayoría de los docentes entrevistados quieren crear una carrera nacional para la docencia, quejándose de una nueva ley. El resultado de la investigación muestral en 38 municipios ha hecho posible confrontar y corroborar toda la encuesta documental, así como acercar la realidad de los profesionales que también trabajan en órganos sindicales, imprescindibles en las luchas por la realización del PSPN. Notamos, en las declaraciones de los maestros sindicalizados, aún con algunas diferencias, el entendimiento de que una política de valorización que abarque el cumplimiento del piso, condiciones de trabajo adecuadas y capacitación inicial y continua, sería fundamental para la categoría. Asimismo, la Carrera Nacional permitiría superar las dificultades generadas por la autonomía descentralizada de la que gozan las entidades federativas, debido a la ausencia de un Sistema Nacional Articulado de Educación. 
Otra conclusión importante de la investigación es que las diferencias entre las diversas partes no son significativas cuando examinamos las referencias a los maestros en los programas de los partidos. De las 32 partes que incluyen la educación entre los temas cubiertos en sus Programas, sólo 12 (34,2\%) hacen alguna referencia a los maestros. Buscando a los que citan "valorización, condiciones de trabajo, salario y capacitación", hay 10 siglas partidistas en la siguiente distribución: 2 izquierda, 3 centro y 3 derecha. Hay pocas diferencias importantes entre los partidos de derecha, los partidos de centro, los partidos de centroizquierda y los partidos de izquierda cuando se trata de discursos en los programas de los partidos y la implementación efectiva de la Ley 11.738/2008. Este es un resultado inesperado, ya que los partidos de centroizquierda e izquierda siempre han estado a la vanguardia de las luchas sindicales y parlamentarias en la defensa del Piso Nacional de Salario Profesional del Magisterio.

En la obra de Florestan Fernandes (1979), buscamos entender la razón de esta pequeña diferencia importante entre los partidos de derecha, centro e izquierda, cuando se trata de la apreciación del maestro. En este caso, respecto a la aplicación de políticas permanentes de valorización del magisterio y la razón de la no aplicación de la Ley del Piso Salarial del Magisterio por parte de los Partidos Políticos, incluidos aquellos que tienen en sus programas la valorización del docente y hablan de ello como un factor decisivo para la calidad de la educación, lo que explica tantas contradicciones entre los discursos y prácticas de los Partidos Políticos cuando se trata de la valorización efectiva del docente?

Para el sociólogo, fundador de la sociología educativa brasileña, diputado constituyente del Partido dos Trabalhadores Florestan Fernandes, teníamos sobre el maestro un rompecabezas para descifrar, que consistía en la tradición de la cosificación y la brutalización cultural de los maestros, propia de la cultura brasileña. Después de citar los escritos de Marx de 1844, Fernandes agrega que en una comparación del maestro con el proletario, es posible afirmar que el maestro fue y sigue siendo objetivado en la sociedad brasileña. Conduit, es un trabajador intelectual que no solo trabaja con sus manos. El reto es, como él dice, buscar una 
comprensión de esta brutalización cultural, que ha estado ocurriendo durante tanto tiempo, y que es aún más pesada cuando se trata de maestros que se dedican a la enseñanza de niños, o maestros de primaria (FERNANDES, 1979).

El sociólogo afirma, aquí y allá, que los miembros laicos y alfabetizados de las capas sociales dominantes son pesimistas sobre la efectividad de las instituciones brasileñas e indiferentes al funcionamiento de las escuelas y con la enseñanza y el trabajo estudiantil (FERNANDES, 1979). Florestan también denuncia una profunda desconfianza de la élite en relación con el intelectual. Para él, la sociedad brasileña es fuertemente desigual y muy jerárquica. Si en el Imperio prevalecía la democracia de los señores, en la República prevalecía la democracia de los oligarcas. La democracia brasileña es limitada y se prescinde de una cultura cívica, ya que sólo una minoría privilegiada tiene acceso a la riqueza, el poder y el conocimiento (FERNANDES, 1989).

Por lo tanto, concluimos que en Brasil, la tradición cultural y el escepticismo parecen ser las causas de la devaluación docente y la incredulidad del poder transformador de la educación.Según Florestan, el escepticismo o dogmatismo sobre el papel de la escuela no significa nada en la dinámica de las transformaciones sociales. Como refuerzo a estas palabras, el educador Dermeval Saviani (1987) advierte de la necesidad de que los dirigentes de los movimientos populares superen la visión de la escuela como un mero instrumento de dominación burguesa, que sólo despierta el interés de la población por su capacidad de promover la ascensión social. En este punto se puede encontrar la respuesta a la diferencia casi insignificante entre los partidos de derecha, centro e izquierda, cuando se trata de la aplicación del Piso Salarial de los Profesionales de la Educación, que no se limita a la remuneración, sino a la carrera, las horas de trabajo, la formación y la valorización de la enseñanza y la consiguiente mejora de la calidad de la educación.

RC: 101661

Disponible: https://www.nucleodoconhecimento.com.br/educacion-es/remuneraciondocente 


\section{REFERENCIAS}

BARBOSA, Andreza; FERNANDES, Maria José da Silva Fernandes. O Piso Salarial em São Paulo: desvalorização dos professores. Retratos da Escola, Brasília, DF, v. 10, n. 18, p. 243-257, jan./jun. 2016.

CAMARGO, Rubens Barbosa de; GOUVEIA, Andréa Barbosa; GIL, Juca; MINHOTO, Maria Angélica Pedra. Financiamento da educação e remuneração docente: um começo de conversa em tempos de piso salarial. Revista Brasileira de Política e Administração da Educação - RBPAE, v. 25, n. 2, p. 341-363, mai./ago. 2009.

FERNANDES, Florestan. O dilema educacional brasileiro. In: PEREIRA, Luiz; FORACCHI, Marialice M. (Orgs.). Educação e sociedade: leituras de sociologia da educação. 10. ed. São Paulo: Nacional, 1979.

FERNANDES, Florestan. O dilema educacional. São Paulo: Cortez; Autores Associados, 1989.

FERNANDES, Maria Dilnéia Espíndola; FERNANDES, Solange Jarcem; CAMPOS, Viviane Gregório de. Remuneração docente: efeitos do Plano de Cargos, Carreira e Remuneração em contexto municipal. Ensaio: Avaliação e Políticas Públicas em Educação, Rio de Janeiro, v. 28, n. 106, p. 25-44, jan./mar. 2020.

FERNANDES, Maria Dilnéia Espíndola; RODRIGUEZ, Margarita Victoria. O processo de elaboração da Lei nº 11.738/2008, Lei do Piso Salarial Profissional Nacional para carreira e remuneração docente: trajetória, disputas e tensões. Revista HISTEDBR On-line, v. 41, p. 88-101, 2011. Disponível em: https://periodicos.sbu.unicamp.br/ojs/index.php/histedbr/article/ view/8639837. Acesso em: 26 set. 2021.

GATTI, Bernardete Angelina; BARRETTO, Elba Siqueira de Sá; ANDRÉ, Marli Eliza Dalmazo de Afonso. Políticas docentes: um estudo da arte. Brasília: Unesco, 2011.

RC: 101661

Disponible: https://www.nucleodoconhecimento.com.br/educacion-es/remuneraciondocente 
GATTI, Elba Siqueira de Sá Barreto. Professores do Brasil: impasses e desafios. Brasília: Unesco, 2009.

GOUVEIA, Andréa Barbosa Gouveia; FERRAZ, Marcos Alexandre dos Santos. Financiamento da educação e luta sindical: conflitos em uma grande rede de ensino. Educação \& Sociedade, Campinas, v. 37, n. 134, p. 285-302, jan.-mar. 2016. Disponível em: https://www.scielo.br/j/es/a/mvMXV3kDKSmkqbWBq3SvQLL/?lang=pt. Acesso em: 26 set. 2021.

GOUVEIA, Andréa Barbosa; FERNANDES, Maria Dilneia Espíndola. Agenda Sindical de Professores da Educação Básica: desafios postos a partir do Piso Salarial Profissional Nacional. Práxis Educativa, Ponta Grossa, v. 14, n. 1, p. 84-98, jan./abr. 2019.

Disponível

em:

http://www.revistas2.uepg.br/index.php/praxiseducativa. Acesso em: 26 set. 2021.

JACOMINI; Márcia Aparecida; PENNA, Marieta Gouvêa de Oliveira Penna. Carreira docente e valorização do magistério: condições de trabalho e desenvolvimento profissional. Pro-posições, v. 27, n. 2, p. 177-202, maio/ago. 2016.

LIMA, Maria José Rocha. A trama da ignorância e outros escritos. Salvador: BDA, 1996.

NASCIMENTO, Ana Paula Santiago do; AMORIM, Renata Rodrigues de; CAMARGO, Rubens Barbosa de. Composição salarial dos docentes da Rede Estadual Paulista: uma análise a partir do Boletim de Acompanhamento de Pessoal da SEE/SP, 1996/2010. Fineduca - Revista de Financiamento da Educação, Porto Alegre, v. 4, n. 7, 2014.

OLIVEIRA, Dalila Andrade. As políticas de formação e a crise da profissionalização docente: por onde passa a valorização? Educação em Questão, Natal, v. 46, n. 32, p. 51-74, 2013.

RC: 101661

Disponible: https://www.nucleodoconhecimento.com.br/educacion-es/remuneraciondocente 
RODRIGUES, Robson da Silva; COSTA, Áurea de Carvalho. Da Constituição Federal de 1988 ao Plano Nacional de Educação 2014-2024: ardilosas apropriações da noção de valorização do trabalho docente. Política \& Trabalho - Revista de Ciências Sociais, n. 50, p. 231-248, jan./jun. 2019.

TEIXEIRA, Eliara Cristina Nogueira da Silva; NUNES, Cláudio Pinto Nunes. O piso salarial como insumo da valorização docente nos governos de FHC e Lula: da Política de Fundos à Lei do Piso. Práxis Educacional, v. 12, p. 251-270, 2016.

\section{APÉNDICE - NOTA DE REFERENCIA}

3. Este artículo forma parte del trabajo de investigación realizado para la Tesis Doctoral en Educación titulada Partidos Políticos e Piso Salarial do Magistério Baiano: no Discurso e na Prática, que se encuentra en la etapa final de preparación y será defendida en la Universidad Internacional Iberoamericana (UNINI).

4. Véase la nota número uno.

5. Véase la nota № 1.

Enviado: Octubre de 2021.

Aprobado: Noviembre de 2021.

RC: 101661

Disponible: https://www.nucleodoconhecimento.com.br/educacion-es/remuneraciondocente 